\title{
Ultrastructural features of hepatocytes in cultured Eurasian perch (Perca fluviatilis L.) as affected by nutritional and husbandry conditions
}

\author{
Gersande Blanchard $^{1 *}$, Jean N. Gardeur ${ }^{2}$, Nicolas Mathis ${ }^{2}$, Jean Brun-Bellut ${ }^{2}$ and Patrick Kestemont ${ }^{1}$ \\ ${ }^{1}$ URBO, Facultés Universitaires N.D. de la Paix, 61 rue de Bruxelles, 5000 Namur, Belgium \\ ${ }^{2}$ URAFPA, Nancy-Université INRA, 34 rue Sainte Catherine, 54000 Nancy, France
}

(Received 3 April 2007 - Revised 31 October 2007 - Accepted 2 November 2007 - First published online 28 February 2008)

A wide range of factors can be attributed to the syndrome of fatty liver observed in some cultured fish species. The objective of the study was therefore to quantify different hepatocyte ultrastructural features as potentially influenced by twelve nutritional and husbandry factors, in order to discriminate the most influent factors in Eurasian perch (Perca fluviatilis), a typical carnivorous temperate fish species. Twenty-four groups of juveniles (initial weight 57.6 (SD 14.4) g) were intensively reared for $116 \mathrm{~d}$ and fed sixteen different isoproteic diets. The distribution of the experimental treatments was based on a multivariate fractional factorial design $\left(\mathrm{L}_{24} 2^{12}\right)$ with either high $(+1)$ or low $(-1)$ level of each of the following factors: diet (lipid and protein sources, lipid content, astaxanthin enrichment), feeding level, daily and weekly distribution frequency, fish density, initial weight heterogeneity, temperature, photoperiod, and light spectrum. Liver lipid droplets, glycogen, mitochondria and rough endoplasmic reticulum (RER) were semi-quantified and analysed by a soft imaging system using transmission electronic microscopy photographs. Important variability of hepatocyte ultrastructural features was observed. The present study confirms that the rearing temperature, through its influences in the general metabolic activity, seems to be the main factor modifying mainly lipid droplet accumulation and RER development. However, factors that could be pooled under the designation of factors leading to food accessibility and lipid and protein quality intensify or compensate the effect of temperature.

Perca fluviatilis: Ultrastructural features of hepatocytes: Nutritional and husbandry factors: Fractional factorial design

During the last few decades there has been a trend in commercial fish feed formulations to increase dietary lipid levels in order to mainly enhance the protein-sparing effect and to improve growth performances and production. More recently, because of the limitation of worldwide fish oil supply, the partial or total replacement of fish oil by vegetable oils is increasingly widespread in fish feed production. However, the use of high-energy diets is known to have a direct influence on the fat deposition in fish, depending on species and age ${ }^{(1,2)}$. Eurasian perch (Perca fluviatilis L.) is a carnivorous species classified as a lean fish, and wild specimens are known to store energy supply mainly as perivisceral fat while muscles contain very little fat, ranging between 1 and $2 \%^{(3-5)}$. However, in culture conditions, percid species are fed diets formulated for salmonids ${ }^{(6,7)}$ or European sea bass ${ }^{(8)}$. Pale and fatty livers as well as unexplained mortality in juvenile production when fed such high-energy diets have been reported ${ }^{(9-12)}$.

Numerous causes are listed in the literature to explain the accumulation of lipids, particularly in the liver, which may eventually cause hepatic steatosis. This condition is described as the presence of lipid microvesicles inside the nucleus and in the lumen of both smooth and rough endoplasmic reticulum (RER). A fatty liver can be the consequence of an imbalanced diet $^{(13-15)}$, a deficiency in dietary fatty acids ${ }^{(16)}$, lipid peroxidation $^{(17)}$ or inadequate culture conditions. However, few studies have examined the simultaneous effects of multiple parameters on lipid liver accumulation.

The liver fulfils numerous functions among which some are related to metabolism, detoxification, digestion or excretion. Lipid assimilation, and glycogen and fat supply management are essential roles played by the organ. According to the principle of the relationship and mutual interaction between structure and function, an alteration of liver structure may be expected to also imply an alteration of liver function ${ }^{(18)}$. So, structural alterations of liver can provide information on the diet quality, diet metabolism and nutritional status of the fish $^{(19)}$.

Until now, fish liver ultrastructure has been mainly investigated in ecotoxicological studies ${ }^{(20-25)}$, but, to our knowledge, very few investigations have been performed using aquaculture-based studies ${ }^{(15,26,27)}$. Based on a multifactorial fractional design, the aim of the present study was to identify, among

Abbreviations: agly, area of glycogen per micrograph; ald, mean area of lipid droplet per micrograph; amit, mean area of mitochondria per micrograph; arer, area of rough endoplasmic reticulum per micrograph; Ast, astaxanthin enrichment; $I_{\mathrm{G}}$, gonadosomatic index; $I_{\mathrm{H}}$, hepatosomatic index; LSF, fish oil as the lipid source; $n l d$, number of lipid droplets per micrograph; PSF, pure fishmeal as the protein source; PSFV, fish and vegetable meal as the protein source; RER, rough endoplasmic reticulum; tld, total area of lipid droplets per micrograph.

* Corresponding author: Dr Gersande Blanchard, fax +3281 724362, email gersande.blanchard@fundp.ac.be 
twelve nutritional and husbandry factors, those that influence ultrastructure hepatocytes in intensively cultured Eurasian perch both individually, and through interactions.

\section{Materials and methods}

\section{Experimental design and diets}

Among numerous factors that are likely to influence the aquaculture system, twelve factors of influence were tested in a fractional factorial experimental design ${ }^{(28-30)}$. The fractional factorial experimental design has already been applied to the study of fish nutrition and reproduction in fish ${ }^{(31-35)}$. Factors and the two tested levels of each factor (Table 1) were defined from data available in the literature ${ }^{(7,8,10,12,36)}$. Temperature, feeding level, diet lipid content, dietary protein and lipid sources, astaxanthin enrichment (Ast), target density, daily distribution frequency, CV of initial weight, photoperiod, light colour and weekly distribution frequency were tested with high or low level $(+1$ and -1$)$ in twenty-four tanks (Table 2).

Each of the twenty-four tanks is the illustration of one unique combination under the 4096 possibilities in case of full factorial design $\left(2^{12}\right)$. This fractional factorial experimental design of resolution IV permits an independent estimation of the constant term and the main effects of the factors as well as estimation by group of two-factor interactions ${ }^{(37,38)}$. The resolution IV used here was obtained by doubling its opposite, i.e. the resolution III of Plackett \& Burman's design with twelve units at two levels ${ }^{(28,39)}$. In practice, we detected discrepancies between sixteen ordered foods and the sixteen actually provided by the supplier (data not shown), and so the twenty-four combinations tested were slightly different from the ones planned (experimental matrix in Table 2). This thus resulted in the loss of both orthogonality and IV resolution. Consequently, factor effect coefficients were dependent, their estimation was less precise (CI higher) and the main effects are confounded with interactions. Consequently, the interpretation of the effect of the main factors will be realised in the form of hypotheses according to the probability that they correspond to main effects alone or to main effects confused with groups of interactions.
The design used four two-level diet factors ( $2^{4}$ combinations), i.e. sixteen different isoproteic diets: the lipid content, the lipid source, the protein source and the Ast (Table 3). Diets (extruded pellets of $3 \mathrm{~mm}$ ) were produced by BioMar (Nersac, France). Fish were fed, according to the experimental design, continuously between 07.00 and 17.00 hours or twice daily at 07.00 and 16.00 hours, by automatic feeders. The feeding levels were established at 22.45 (optimal feeding) and $30.67 \%$ (maximal feeding) of body weight ${ }^{-068(7,36)}$.

\section{Fish and facilities}

Before the experiment, Eurasian perch ( $P$. fluviatilis) juveniles originating from the Centre of Education and Research in Aquaculture (Tihange, Belgium) were reared in a recirculating system under the following conditions: temperature $20-24^{\circ} \mathrm{C}$; dissolved $\mathrm{O}_{2} 7.5$ and $9.5 \mathrm{mg} / \mathrm{l} ; 12 \mathrm{~h}$ light $-12 \mathrm{~h}$ dark photoperiod. Fish were fed by hand with a commercial diet (TROUVIT Classic; Fontaine Les Jervins, France) twice daily, at an optimal feeding level ${ }^{(7)}$. The experiment was conducted during 15 weeks at the Animal Functionality of Animal Products Research Unit (Nancy University, Nancy, France). A single batch of 804 fish weighing between 30 and $85 \mathrm{~g}$ (average weight 57.6 (SD 14.4) g) was graded into eleven weight classes of $5 \mathrm{~g}$. From these classes, 536 fish were allocated into twenty-four experimental units (tanks) in such a way that tanks contained fish of the same initial average weight, low or high initial weight heterogeneity and low or high target total biomass (twenty-five or forty-two fish per tank, respectively). The twenty-four tanks of $0.5 \mathrm{~m}^{3}$, each operating independently as a recirculating system, were made with light blue polyvinyl chloride (PVC). They were distributed into four experimental rooms. Water temperatures were maintained either at $16^{\circ} \mathrm{C}$ (air-conditioned rooms) or at $23^{\circ} \mathrm{C}$ (heating resistors). All tanks were covered with opaque cages $80 \mathrm{~cm}$ high to protect fish against external light and disturbances. At the top of each experimental unit were placed a band automatic feeder and an individual light (industrial white or violet). Fish were exposed to an $8 \mathrm{~h}$ light and $16 \mathrm{~h}$ dark or a $16 \mathrm{~h}$ light and $8 \mathrm{~h}$ dark photoperiod according to the experimental design.

Table 1. Twelve factors and their levels tested in the fractional factorial experiment with juvenile Eurasian perch (Perca fluviatilis L.)

\begin{tabular}{|c|c|c|}
\hline \multirow[b]{2}{*}{ Factors } & \multicolumn{2}{|c|}{ Levels } \\
\hline & +1 & -1 \\
\hline Photoperiod (Pho) & 16/8 (Pho16) & 8/16 (Pho8) \\
\hline Light spectrum (LSpect) & Industrial white (Lspectl) & Violet (LSpectV) \\
\hline Expected final density (Dens) & $12 \mathrm{~kg} / \mathrm{m}^{3}$ (Dens 12) & $4 \mathrm{~kg} / \mathrm{m}^{3}$ (Dens 4$)$ \\
\hline Initial heterogeneity (Het) & $30 \%($ Het30) & $15 \%($ Het15) \\
\hline Daily distribution frequency (DDF) & Two meals at 07.00 and 16.00 hours (DDF2) & Continuously between 07.00 and 17.00 hours (DDFC) \\
\hline Weekly distribution frequency (WDF) & All days of the week (WDF7) & $6 \mathrm{~d}$ of the week (WDF6) \\
\hline Food lipid content (Lip) & $21 \%$ wet-weight basis (Lip21) & $17 \%$ wet-weight basis (Lip17) \\
\hline Astaxanthin content (Ast) & $0.4 \%($ AstT $)$ & $0 \%$ (AstO) \\
\hline Lipid source (LS) & Rapeseed oil (LSV) & Menhaden oil (LSF) \\
\hline Protein source (PS) & Fish + soya meal (PSFV) & Fish meal (PSF) \\
\hline
\end{tabular}


Table 2. Twenty-four experimental combinations tested in the fractional factorial experiment with juvenile Eurasian perch (Perca fluviatilis L.)

\begin{tabular}{|c|c|c|c|c|c|c|c|c|c|c|c|c|c|}
\hline Combi & Diet & Temp & $\mathrm{FL}$ & Lip & PS & LS & Ast & Dens & DDF & Het & Pho & Lspec & WDF \\
\hline 24 & 14 & 23 & opt & 21 & $F$ & $\mathrm{~F}$ & 0 & 12 & 2 & 30 & 16 & 1 & 7 \\
\hline 17 & 3 & 23 & opt & 17 & FV & V & $\mathrm{T}$ & 12 & $\mathrm{C}$ & 15 & 8 & I & 7 \\
\hline 18 & 10 & 23 & opt & 17 & $\mathrm{~F}$ & $\mathrm{~F}$ & 0 & 4 & 2 & 15 & 8 & V & 7 \\
\hline 1 & 6 & 23 & opt & 21 & FV & $\mathrm{F}$ & O & 4 & $\mathrm{C}$ & 15 & 16 & V & 6 \\
\hline 3 & 15 & 23 & $\max$ & 21 & $\mathrm{~F}$ & V & $\mathrm{T}$ & 12 & 2 & 15 & 8 & V & 6 \\
\hline 11 & 9 & 23 & $\max$ & 17 & $\mathrm{~F}$ & V & $\mathrm{O}$ & 4 & C & 30 & 8 & 1 & 6 \\
\hline 8 & 8 & 23 & opt & 21 & FV & $\mathrm{F}$ & $\mathrm{T}$ & 4 & 2 & 30 & 8 & 1 & 6 \\
\hline 9 & 11 & 23 & opt & 17 & $\mathrm{~F}$ & V & $\mathrm{T}$ & 12 & $C$ & 30 & 16 & V & 6 \\
\hline 16 & 16 & 23 & $\max$ & 21 & $\mathrm{~F}$ & $\mathrm{~F}$ & $\mathrm{~T}$ & 4 & $C$ & 15 & 16 & 1 & 7 \\
\hline 22 & 5 & 23 & $\max$ & 21 & FV & V & 0 & 12 & $\mathrm{C}$ & 30 & 8 & V & 7 \\
\hline 14 & 3 & 23 & $\max$ & 17 & FV & V & $\mathrm{T}$ & 4 & 2 & 30 & 16 & V & 7 \\
\hline 7 & 1 & 23 & $\max$ & 17 & FV & $\mathrm{V}$ & 0 & 12 & 2 & 15 & 16 & I & 6 \\
\hline 4 & 2 & 16 & opt & 17 & FV & $\mathrm{F}$ & 0 & 12 & 2 & 30 & 8 & V & 6 \\
\hline 2 & 13 & 16 & opt & 21 & $\mathrm{~F}$ & V & 0 & 12 & C & 15 & 8 & 1 & 6 \\
\hline 21 & 6 & 16 & $\max$ & 21 & FV & $\mathrm{F}$ & 0 & 4 & 2 & 15 & 8 & I & 7 \\
\hline 12 & 4 & 16 & $\max$ & 17 & FV & $\mathrm{F}$ & $\mathrm{T}$ & 4 & $\mathrm{C}$ & 15 & 8 & V & 6 \\
\hline 15 & 1 & 16 & opt & 17 & FV & V & 0 & 4 & $\mathrm{C}$ & 30 & 16 & I & 7 \\
\hline 6 & 7 & 16 & $\max$ & 21 & FV & $\mathrm{V}$ & $\mathrm{T}$ & 12 & $\mathrm{C}$ & 30 & 16 & $i$ & 6 \\
\hline 10 & 12 & 16 & opt & 17 & $F$ & $\mathrm{~F}$ & $\mathrm{~T}$ & 4 & 2 & 15 & 16 & 1 & 6 \\
\hline 19 & 15 & 16 & opt & 21 & $\mathrm{~F}$ & $\mathrm{~V}$ & $\mathrm{~T}$ & 4 & $\mathrm{C}$ & 30 & 8 & V & 7 \\
\hline 23 & 8 & 16 & opt & 21 & FV & $\mathrm{F}$ & $\mathrm{T}$ & 12 & 2 & 15 & 16 & V & 7 \\
\hline 5 & 13 & 16 & $\max$ & 21 & $\mathrm{~F}$ & $\mathrm{~V}$ & 0 & 4 & 2 & 30 & 16 & V & 6 \\
\hline 20 & 9 & 16 & $\max$ & 17 & $F$ & $\mathrm{~V}$ & 0 & 12 & $\mathrm{C}$ & 15 & 16 & V & 7 \\
\hline 13 & 11 & 16 & $\max$ & 17 & $F$ & V & $\mathrm{T}$ & 12 & 2 & 30 & 8 & 1 & 7 \\
\hline
\end{tabular}

Combi, combinations; Temp, temperature at 23 or $16^{\circ} \mathrm{C}$; FL, optimal (opt) or maximal (max) feeding level; Lip, lipid content at 21 or $17 \%$ of lipid in the diet; PS and LS, protein and lipid sources with fishmeal (F) or fish + soya meal (FV) and menhaden oil (F) or rapeseed oil (V), respectively; Ast, astaxanthin enrichment with $0 \%(\mathrm{O})$ or $0.4 \%(\mathrm{~T})$; Dens, fish density at $4 \mathrm{~kg} / \mathrm{m}^{3}(4)$ or $12 \mathrm{~kg} / \mathrm{m}^{3}(12)$; DDF, daily distribution frequency, two times per d (2) or continuously (C); Het, initial weight heterogeneity at 30 or $15 \%$; Pho, photoperiod with $16 \mathrm{~h}$ light (16) or $8 \mathrm{~h}$ light (8) per d; LSpect, light spectrum with industrial white (I) or violet (V); WDF, weekly distribution frequency all days of the week (7) or $6 \mathrm{~d}$ of the week (6).

\section{Sampling procedure}

At the beginning of the experiment and every 5 weeks until the end of the experiment, biomass and average weight were determined by bulk weighing and counting of all fish in each tank. This manipulation was also necessary in order to adjust the feeding level, as a percentage of biomass. During rearing, water temperature and $\mathrm{O}_{2}$ content were monitored daily after the first feeding period. Ammonium ion and nitrites $\left(\mathrm{N}-\mathrm{NH}_{4}^{+}\right.$and $\left.\mathrm{N}-\mathrm{NO}_{2}^{-}\right)$were measured twice per week ${ }^{(40)}$ and nitrate and phosphate contents weekly. Mortalities were recorded and dead fish removed daily. At the end of experiment (116d), individual measurements were carried out on fifteen fish per tank chosen at random from each tank and for which the final fresh weight was included in the interval of the average $\pm 2 \mathrm{SD}$. Fish were immediately killed by cold shock combined with overdose of anaesthetic (i.e. phenoxy-ethanol; $3 \mathrm{ml} / \mathrm{l})$, weighed ( $\mathrm{g}$ ) and dissected. The hepatosomatic index $\left(I_{\mathrm{H}}\right)$, gonadosomatic index $\left(I_{\mathrm{G}}\right)$ and liposomatic index (morphological criteria) were calculated as:

$$
y=100 \times \frac{x}{M}
$$

Table 3. Composition (\%) of the sixteen different diets used in the fractional factorial experiment with juvenile Eurasian perch (Perca fluviatilis L.)

\begin{tabular}{|c|c|c|c|c|c|c|c|c|c|}
\hline Diets & Fishmeal & Soya meal & Maize & Menhaden oil & Rapeseed oil & Astaxanthin & Maize meal & Vitamin mix & Lecithin \\
\hline 1 & 43 & 30 & 14.9 & - & $10 \cdot 5$ & - & 0.78 & 0.42 & 0.4 \\
\hline 2 & 43 & 30 & 14.9 & $10 \cdot 5$ & - & - & 0.78 & 0.42 & 0.4 \\
\hline 3 & 43 & 30 & 14.5 & - & $10 \cdot 5$ & 0.4 & 0.78 & 0.42 & 0.4 \\
\hline 4 & 43 & 30 & 14.5 & $10 \cdot 5$ & - & 0.4 & 0.78 & 0.42 & 0.4 \\
\hline 5 & $43 \cdot 5$ & 30 & $8 \cdot 4$ & - & $16 \cdot 5$ & - & 0.78 & 0.42 & 0.4 \\
\hline 6 & $43 \cdot 5$ & 30 & 8.4 & $16 \cdot 5$ & - & - & 0.78 & 0.42 & 0.4 \\
\hline 7 & $43 \cdot 5$ & 30 & 8 & - & $16 \cdot 5$ & 0.4 & 0.78 & 0.42 & 0.4 \\
\hline 9 & 60 & - & $28 \cdot 4$ & - & 10 & - & 0.78 & 0.42 & 0.4 \\
\hline 10 & 60 & - & $28 \cdot 4$ & 10 & - & - & 0.78 & 0.42 & 0.4 \\
\hline 11 & 60 & - & 28 & - & 10 & 0.4 & 0.78 & 0.42 & 0.4 \\
\hline 12 & 60 & - & 28 & 10 & - & 0.4 & 0.78 & 0.42 & 0.4 \\
\hline 13 & 61 & - & 21.9 & - & $15 \cdot 5$ & - & 0.78 & 0.42 & 0.4 \\
\hline 14 & 61 & - & 21.9 & $15 \cdot 5$ & - & - & 0.78 & 0.42 & 0.4 \\
\hline 15 & 61 & - & 21.5 & - & $15 \cdot 5$ & 0.4 & 0.78 & 0.42 & 0.4 \\
\hline 16 & 61 & - & 21.5 & $15 \cdot 5$ & - & 0.4 & 0.78 & 0.42 & 0.4 \\
\hline
\end{tabular}


where $y$ is the index, $M$ is the mass ( $\mathrm{g}$ ) of the fish, and $x$ is the mass $(\mathrm{g})$ of the liver, gonad or perivisceral fat (compacted fat was easily collected around the digestive tract).

Specific growth rate $(\% / d)$ was calculated as follows:

$$
\text { Specific growth rate }=100 \times \frac{\left(\operatorname{Ln}\left(W_{\mathrm{f}}\right)-\operatorname{Ln}\left(W_{\mathrm{i}}\right)\right)}{\Delta T},
$$

where $W_{\mathrm{i}}$ and $W_{\mathrm{f}}$ are initial and final weights $(\mathrm{g})$, respectively, and $\Delta T$ is the duration of the experiment (d).

Samples of diets $(5 \mathrm{~g})$ and muscles were stored frozen under vacuum at $-80^{\circ} \mathrm{C}$ before analysis. The livers of three females per tank were randomly harvested for electron microscopy analysis.

\section{Analytical procedures}

Muscle samples were ground and homogenised. Total lipids from diets and from muscles were extracted in duplicate with dichloromethane-methanol $(2: 1, \mathrm{v} / \mathrm{v})$ according to Folch et al. ${ }^{(41)}$ modified according to Chen et al. ${ }^{(42)}$. An antioxidant (butylhydroxytoluene) was added at $0.01 \%$ during the analysis to avoid peroxidation. The fatty acids of total lipids were converted to methyl esters by acid-catalysed transmethylation according to Santha \& Ackman $^{(43)}$ and analysed by GC (GC trace, Varian, 3400) using a $30 \mathrm{~m} \times 0.25 \mathrm{~mm}$ capillary column (DB-Wax). The carrier gas was $\mathrm{He}(0.9 \mathrm{ml} / \mathrm{min})$ and temperature programming was from 180 to $240^{\circ} \mathrm{C}$ at $4^{\circ} \mathrm{C} / \mathrm{min}$, and then during $10 \mathrm{~min}$ at $240^{\circ} \mathrm{C}$. The injection and detection temperatures were 260 and $250^{\circ} \mathrm{C}$, respectively. Peak identification and quantification were done in a calibrated plotter integrator by comparing with known reference standards (Sigma). Crude protein content of diets was determined using the Kjeldahl method $(\mathrm{N} \times 6 \cdot 25)$.

\section{Tissue preparation}

Liver specimens were randomly harvested from three additional females of each tank in order to analyse the hepatocyte ultrastructure. In each liver, more than ten random samples were minced to $1 \mathrm{~mm}^{3}$ blocks in $2.5 \%$ glutaraldehyde in $0.1 \mathrm{M}$-cacodylate buffer ( $\mathrm{pH} \mathrm{7.4)}$. The blocks were fixed for $150 \mathrm{~min}$ at $4^{\circ} \mathrm{C}$, rinsed three times $(60 \mathrm{~min})$ in 0.2 M-cacodylate buffer, post-fixed for $60 \mathrm{~min}$ in $1 \%$ osmium tetroxide $\left(\mathrm{OsO}_{4}\right)$ prepared in cacodylate buffer, washed three times $(30 \mathrm{~min})$ in $0.1 \mathrm{M}$-cacodylate buffer $(\mathrm{pH}$ 7.4 ), placed at $4^{\circ} \mathrm{C}$ overnight, dehydrated through a graded series of ethanol, cleared in propylene oxide and embedded in LX 112. Thick sections (about $2 \mu \mathrm{m}$ ) of embedded tissue from two blocks from the three females of each tank were prepared on an LKB pyramitome, mounted on glass slides, and stained with $1 \%$ toluidine blue for light microscopy. Thin sections were cut at approximately $50 \mathrm{~nm}$ on a LKB ultramicrotome and mounted on 200 mesh, uncoated, $\mathrm{Cu}-\mathrm{Pd}$ grids. The sections were counterstained with uranyl acetate $4 \%$ (prepared in $50 \%$ ethanol) and lead citrate, and examined with a Philips Tecnai electron microscope. Sixty electron micrographs per tank were obtained from a randomly selected area per grid (two grids per block, two blocks per female and three females per tank). Each micrograph was subsequently examined to obtain measures of organelle numbers and/or areas that provide an estimate of the organelle importance according to treatments. Results are expressed as number of lipid droplets per micrograph $(n l d)$, mean area of lipid droplet per micrograph (ald; $\left.\mu \mathrm{m}^{2}\right)$, total area of lipid droplets per micrograph $(t l d)(t l d=$ nld $\times$ ald $\left(\mu \mathrm{m}^{2}\right)$ ), area of glycogen per micrograph (agly; $\mu \mathrm{m}^{2}$ ), area of RER per micrograph (arer; \%), number of mitochondria per micrograph (nmit) and mean area of mitochondria per micrograph (amit; $\mu \mathrm{m}^{2}$ ). The micrograph surface was $320 \mu \mathrm{m}^{2}$ with constant magnification. Organelles were semi-quantified and measured using a soft imaging system (AnalySIS 3.0; AnalySIS GmbH, Munster, Germany). Automatic identification of lipid droplets and glycogen particles was made after the definition of an amplitude variation on colour pixels as well as of a minimum size particles to take into account. Because of the very similar grey tonality between some organelles and cytoplasm, the analysis of mitochondria was done manually with the help of a graphics tablet and pen (Wacom Intuos 2 Model XD-0912-U; Wacom Europe GmbH, Krefeld, Germany). Finally, in order to evaluate the area of RER, a grid of 320 squares of $1 \mu \mathrm{m}^{2}$ was virtually superimposed on the electron micrograph. Evaluation of RER area was made by counting the number of squares containing at least $50 \%$ of the organelle.

\section{Statistical analysis}

Statistical analyses were carried out with Analys software $^{(44)}$. The detection of the potentially active effects of tested factors on the output variables was given by Daniel's graphics (half normal probability plot of basal estimation function) $^{(45)}$ using an oversaturated model of variance analysis. An ANOVA was next performed, setting the potential influent factors for each variable as part of the model and calculating the reference mean square results from the nonactive contrasts $(P<0 \cdot 05)$. The Results present the effects of factors and their interactions. The impact of the factor on the measured variable expressed in percentage of variability $\left(R^{2}\right)$ is indicated and followed by the significance of the test (significant effect with $P<0.05$; highly significant effect with $P<0.01$; very highly significant effect with $P<0.001)$. Levels and their correspondences are presented in Table 1.

\section{Results}

\section{Description of ultrastructural hepatocyte features}

The twenty-four factor combinations tested in the present experiment generated a wide range of hepatic features. Parenchymal cells were preserved or degenerated and unstructured. Nuclei were generally round and contours smooth with intermembrane spaces not inflated or deformed with inflated intermembrane spaces. Nuclei were generally centrally located in the hepatocyte with a single nucleolus, but intermediate or opposite situations occurred with nuclei located at the periphery of the hepatocyte. Content of RER in the parenchymal cells ranged between 0.7 and $14.7 \%$ of the micrograph surfaces (Fig. 1 (A) and (B)). The RER was arranged usually in parallel stack cisternae around the nucleus. Sometimes cisternae were inflated (Fig. 1 (C)) or very inflated without 

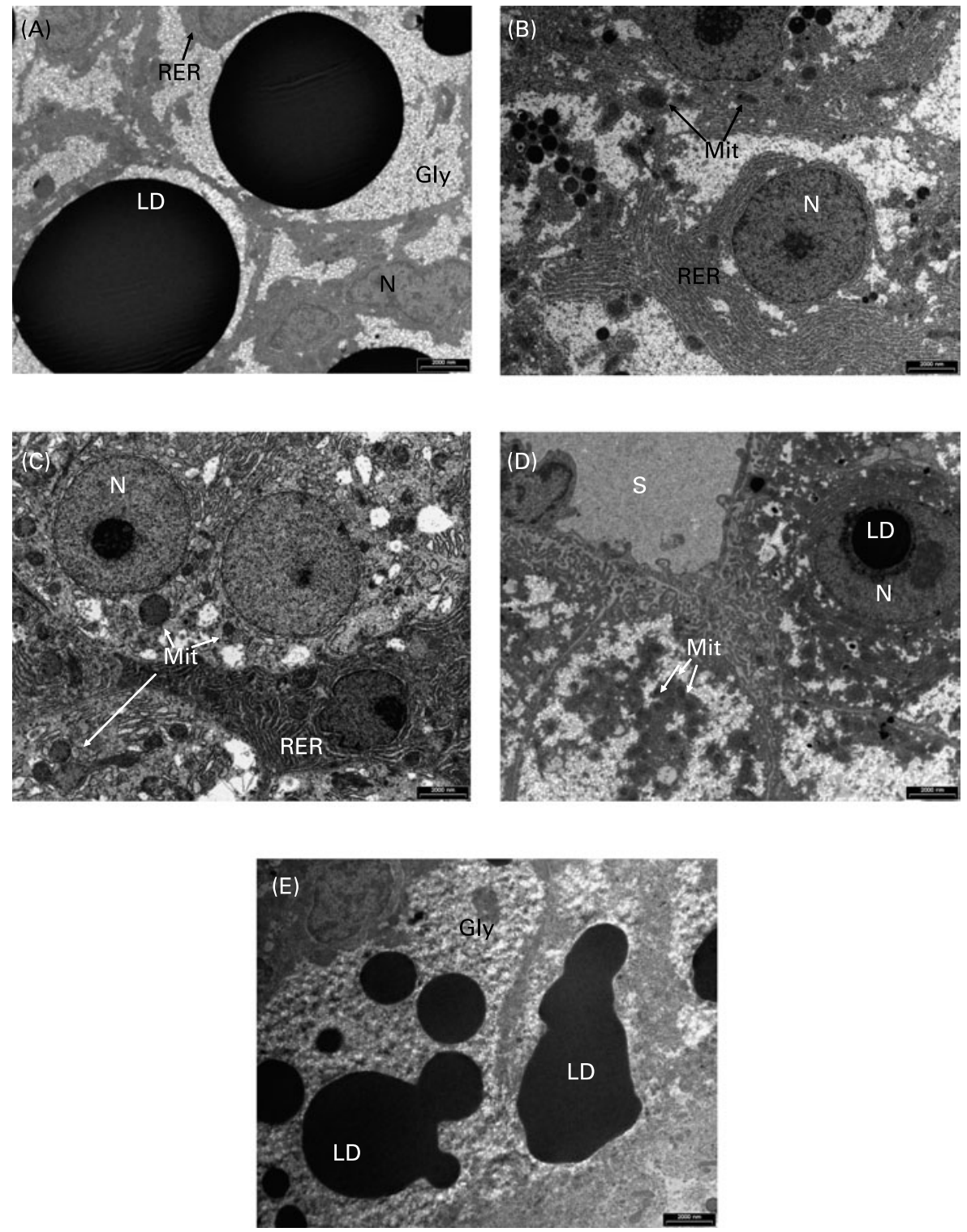

Fig. 1. Electron micrograph of female juvenile Eurasian perch (Perca fluviatilis L.) hepatocytes reared under the combination of twelve nutritional and husbandry factors. (A) Hepatocytes with low content of rough endoplasmic reticulum (RER) and large lipid droplets (LD) nearly filling the cytoplasm. (B) Hepatocytes with a large content of RER arranged in parallel stack cisternae around the nucleus $(\mathrm{N})$ and without lipid droplets. (C) Hepatocytes with RER cisternae and mitochondria (Mit) inflated. (D) Hepatocytes with numerous mitochondria not inflated and abnormal intranuclear inclusions of lipid droplets. (E) Hepatocytes with lipid droplets probably in fusion in the cytoplasm. Gly, glycogen; $\mathrm{S}$, sinusoidal blood space.

parallel organisation. Vesicular RER distributed in clusters in the cytoplasm was also observed. Mitochondria were distributed throughout the cytoplasm, elongated or rounded, sometimes inflated with a pale matrix and often surrounded by a circle of RER. Mitochondria could be found in contact with myelinoid formations corresponding to a type of mitochondria degeneration. Number and mean area of this organelle ranged between 14 and 67 , and 0.16 and $0.40 \mu \mathrm{m}^{2}$, respectively (Fig. 1 (D) and (C)). Glycogen was aggregated in the cytoplasm forming large concretions ranging between 18.1 and $127.5 \mu \mathrm{m}^{2}$ of the parenchymal cell surfaces. Lipid could be found as small- to medium-sized droplets interspersed with the organelles in the parenchymal cells, or nearly filling the cytoplasm of the cells (Fig. 1 (B) and (A), respectively). The $t l d$ ranged between 1.4 and $106.3 \mu \mathrm{m}^{2}$. In the case of the highest area, other organelles were usually crushed at the periphery of the hepatocytes or simply absent. Some abnormal intranuclear inclusions of lipid droplets were also observed (Fig. 1 (D)). Figure 1 (E) shows the possible fusion between lipid droplets in the cytoplasm. Results illustrated the plasticity of perch liver, ranging, in rearing conditions, from typical cytological features of wild fish to the so-called fat-storing cells.

Organelles undergoing most of the influences of the twentyfour combined experimental conditions applied in the present study were lipid droplets displaying CV equal to 99, 93 and $76 \%$ for the tld, ald and nld, respectively. Results of arer also displayed high CV between combinations (67\%) followed, to a lesser extent, by agly, nmit and amit (39, 30 and $27 \%$, respectively). 
Correlations between ultrastructural hepatocyte features themselves and biological variables

Each of the ultrastructural hepatocyte features may be related to the others. Positive significant correlation was established between the tld and the nld ( $r 0.79 ; P<0.05$; Fig. 2). Growth performance (specific growth rate) was positively correlated with the hepatic accumulation of lipid droplets (tld) $(r \quad 0.7 ; \quad P<0.05 ;$ Fig. 3 (A)). When lipid droplet accumulation increased $(t l d), I_{\mathrm{G}}$ decreased $(r-0.7 ; P<0.05$; Fig. 3 (B)) while liposomatic index increased ( $r$ 0.8; $P<0.05$; Fig. 3 (C)). RER development (arer) was positively correlated with the $I_{\mathrm{G}}(r 0.7 ; P<0 \cdot 05$; Fig. 3 (D)).

\section{Factor effects on hepatocyte ultrastructure}

Among the twelve nutritional and husbandry factors tested, rearing temperature was by far the one that most frequently affected hepatocyte ultrastructure. The effect of temperature on tld $\left(\mu \mathrm{m}^{2}\right)$ reached $61 \%(P<0 \cdot 001)$. So, according to rearing temperature, tld ranged between 6.4 and $45.3 \mu \mathrm{m}^{2}$ at 16 and $23^{\circ} \mathrm{C}$, respectively (Fig. 4). In the case of the remaining hepatocyte features, the effects of temperature were always strongest, and they were observed along with other factors. These sometimes interacted with temperature, or with each other. For example, temperature and density both influenced the nld $\left(R^{2} 30 \%(P<0.001)\right.$ and $12 \%(P<0.01)$, respectively) as presented in Fig. 5. In addition, the $n l d$ was affected by interactions between temperature and protein source $\left(R^{2} 16 \% ; P<0.001\right)$, protein source and daily distribution frequency $\left(R^{2} 13 \% ; P<0 \cdot 01\right)$ and temperature and daily distribution frequency $\left(R^{2} 9 \% ; P<0.01\right)$ (Fig. 6). Higher $n l d$ (8.0) were obtained at $23^{\circ} \mathrm{C}$ in fish fed pure fishmeal as the protein source (PSF) and lower nld (1.6) at $16^{\circ} \mathrm{C}$ in fish fed fish and vegetable meal as the protein source (PSFV). The effect of temperature was less pronounced $(4.3$ v. $3.6 \mathrm{nld}$ at 23 and $16^{\circ} \mathrm{C}$, respectively) in the case of mixed protein source (PSFV). An increase in the $n l d$ was observed at $16^{\circ} \mathrm{C}$ in fish fed continuously compared with those fed twice per $\mathrm{d}$ $\left(1.7\right.$ v. 3.4), but a decrease at $23^{\circ} \mathrm{C}(7.4$ v. 5.0). The third interaction between protein source and daily distribution frequency $\left(R^{2} 13 \% ; P<0 \cdot 01\right)$ was associated with an increase of the $n l d$ in fish fed fish and vegetable meal (PSFV) continuously, compared with twice daily $(2.9 v$ v. 5.0). The opposite was observed when fish were fed PSF in the diets (6.2 v. 3.4, respectively).

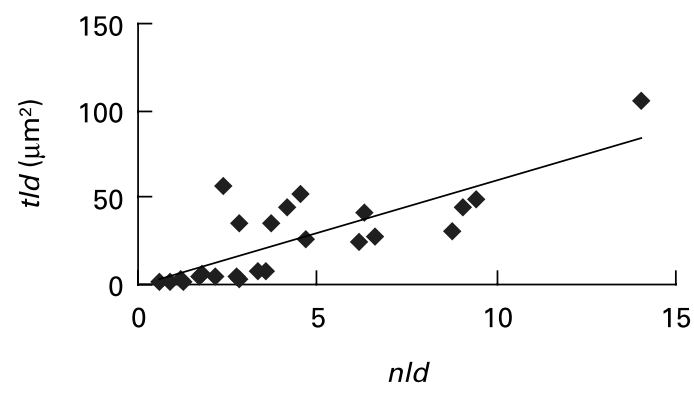

Fig. 2. Correlation $(r 0.79 ; P<0.05)$ between ultrastructural hepatocyte features of female Eurasian perch (Perca fluviatilis L.). nld, Number of lipid droplets per micrograph; $t / d$, total area of lipid droplets per micrograph $\left(t / d=n / d \times\right.$ ald $\left(\mu \mathrm{m}^{2}\right)$ where ald is the mean area of lipid droplet per micrograph $\left.\left(\mu \mathrm{m}^{2}\right)\right)$.
Concerning the area of lipid droplets per particle (ald; $\mu \mathrm{m}^{2}$ ), temperature was also the main factor affecting the results $\left(R^{2} 43 \% ; P<0.001\right)$, followed by lipid source $\left(R^{2} 9 \% ; P<0.01\right)$, weekly distribution frequency $\left(R^{2} 8 \%\right.$; $P<0.01)$ and light spectrum $\left(R^{2} 5 \% ; P<0 \cdot 01\right)$. But, they act in interaction. Interaction effects between these factors show that the effect of weekly distribution frequency was very low at $16^{\circ} \mathrm{C}$ or with rapeseed oil as the lipid source or with violet light and that the effect of lipid source was very low at $16^{\circ} \mathrm{C}$ (Fig. 7). At the opposite levels, interaction effects were much more pronounced.

The arer (\%) was significantly affected by three main factors: temperature $\left(R^{2} 43 \% ; P<0.001\right)$, fish initial heterogeneity $\left(R^{2} 10 \% ; P<0 \cdot 01\right)$ and lipid source $\left(R^{2} 6 \% ; P<0.05\right)$, and they act in interaction. Interactions between these main factors show that fish initial heterogeneity and lipid source effects were very low at $23^{\circ} \mathrm{C}$ (Fig. 8). For example, the arer was less influenced by rearing temperature (4.9 and $3.3 \%$ at $16 v .23^{\circ} \mathrm{C}$, respectively) considering fish fed rapeseed oil in the diet compared with fish fed pure fish oil in the diet (LSF) $\left(10.3\right.$ and $2.0 \%$ at 16 and $23^{\circ} \mathrm{C}$, respectively) $\left(R^{2} 17 \%\right.$; $P<0.001)$.

In contrast to the previous ultrastructural features ( $n l d$, ald,

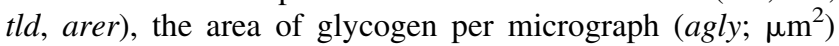
was mainly affected by daily distribution frequency $\left(R^{2} 23 \% ; P<0 \cdot 001\right)$, lipid source $\left(R^{2} 8 \% ; P<0.05\right)$ and protein source $\left(R^{2} 8 \% ; P<0.05\right)$ (Fig. 9). In other words, glycogen storage was more important in fish fed twice per $\mathrm{d}$ or with a diet containing menhaden oil (LSF) or fishmeal (PSF) than at the opposite levels. However, temperature also modified other effects (with inversion) such as photoperiod (temperature-photoperiod, $R^{2} 17 \%$; $P<0 \cdot 01$ ), diet lipid content (temperature-lipid content, $\left.R^{2} 11 \% ; P<0.05\right)$ and Ast (temperature-Ast, $R^{2} 11 \%$; $P<0.05$ ) (Fig. 10). With $16 \mathrm{~h}$ of light or $21 \%$ of lipid or $0 \%$ astaxanthin, glycogen storage increases with higher temperature; however, with $8 \mathrm{~h}$ of light or $17 \%$ of lipid or $0.4 \%$ astaxanthin, glycogen storage decreases with higher temperature.

The nmit was affected by temperature $\left(R^{2} 10 \% ; P<0.05\right)$, protein source $\left(R^{2} 10 \% ; P<0 \cdot 05\right)$, photoperiod $\left(R^{2} 10 \%\right.$; $P<0.05)$ and Ast $\left(R^{2} 9 \% ; P<0.05\right)$ (Fig. 11). A temperature of $16^{\circ} \mathrm{C}$, protein source of fish and soya meal (PSFV), $8 \mathrm{~h}$ of light and Ast of $0.4 \%$ led to a higher number of mitochondria in comparison with opposite levels. Significant interaction effects between temperature and protein source factors (temperature-protein source, $\left.R^{2} 12 \% ; P<0.05\right)$ suggested that the effect of temperature is mainly observed when diets contain fishmeal (Fig. 12). The amit $\left(\mu \mathrm{m}^{2}\right)$ was not affected by rearing temperature. However, Ast $\left(R^{2} 19 \% ; P<0.001\right)$, daily distribution frequency $\left(R^{2} 7 \% ; P<0.01\right)$ or diet lipid content $\left(R^{2} 4 \% ; P<0.05\right)$ all significantly influenced amit. Numerous interactions between these main factors and protein source and lipid source factors show that amit decreased with $0.4 \%$ Ast in the diet mostly in the case of menhaden oil (LSF) or fishmeal (PSF) or $17 \%$ lipid in the diets, continuously distributed during the day, rather than with the opposite levels (Ast-lipid source, $R^{2} 18 \%(P<0.001)$; protein source-Ast, $R^{2} 19 \%(P<0.001)$; Ast-daily distribution frequency, $R^{2}$ $5 \%(P<0.05)$; lipid content-Ast, $R^{2} 5 \%(P<0.05)$, respectively) (Fig. 13). With $21 \%$ of lipids in the diet, the effect of weekly distribution frequency on the area of mitochondria 

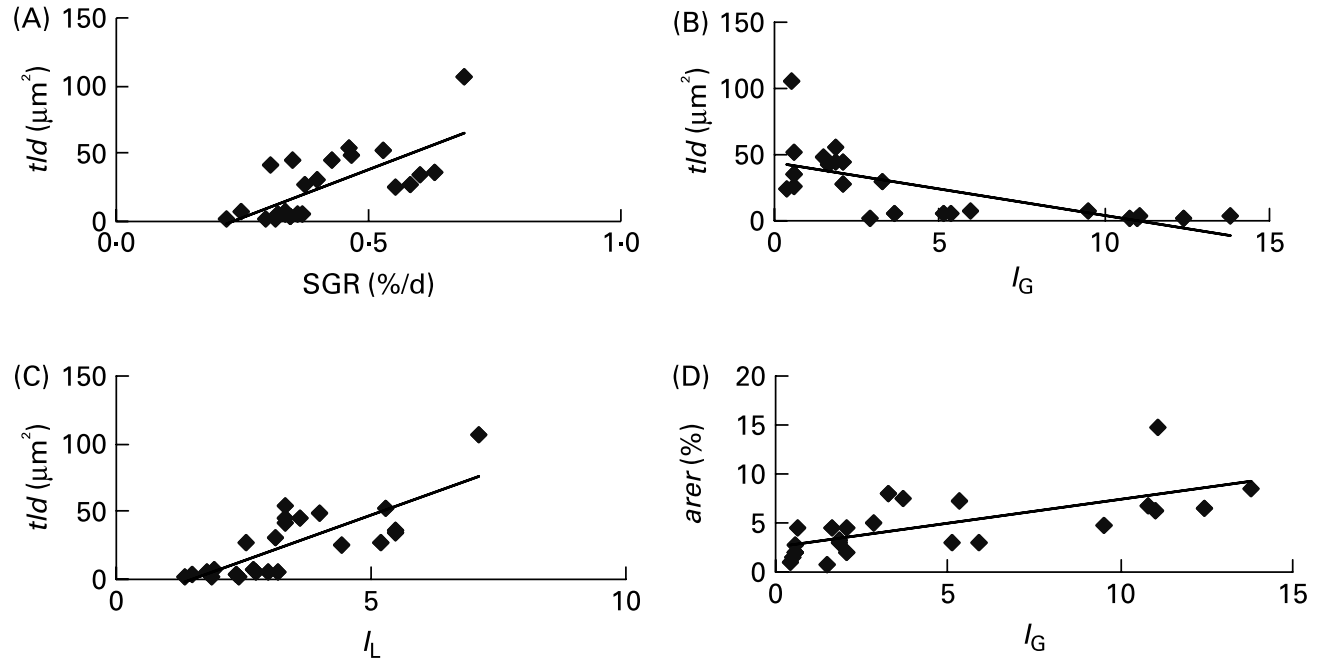

Fig. 3. Correlations between ultrastructural hepatocyte features and biological variables of female juvenile Eurasian perch (Perca fluviatilis L.). (A) Correlation of specific growth rate (SGR; \%/d) and total area of lipid droplets per micrograph $(t / d)(r 0.7 ; P<0.05)$. SGR $=100 \times\left(\operatorname{Ln}\left(W_{\mathrm{f}}\right)-\operatorname{Ln}\left(W_{\mathrm{i}}\right)\right) / \Delta T$, where $W_{\mathrm{i}}$ and $W_{\mathrm{f}}$ are the initial and final weights $(\mathrm{g})$, respectively, and $\Delta T$ is the duration of the experiment $(\mathrm{d}) ; t / d=n / d \times$ ald $\left(\mu \mathrm{m}^{2}\right)$, where $n / d$ is the number of lipid droplets per micrograph and ald is the mean area of lipid droplet per micrograph $\left(\mu \mathrm{m}^{2}\right)$. (B) Correlation of gonadosomatic index $\left(I_{\mathrm{G}}\right)$ and $t / d(r-0 \cdot 7 ; P<0 \cdot 05)$. (C) Correlation of liposomatic index $\left(I_{\mathrm{L}}\right)$ and $t / d(r 0.8 ; P<0.05)$. (D) Correlation of $I_{\mathrm{G}}$ and area of rough endoplasmic reticulum per micrograph $(\%)($ are $r)(r 0.7 ; P<0.05)$. The $I_{\mathrm{G}}$ and the $I_{L}$ (morphological criteria) are calculated as $y=100 \times x / M$, where $y$ is the index, $M$ is the mass $(\mathrm{g})$ of the fish, and $x$ is the mass ( $\mathrm{g}$ ) of the gonad or perivisceral fat.

was lower than in case of $17 \%$ lipid content (daily distribution frequency-lipid content, $\left.R^{2} 9 \% ; P<0.01\right)$. The amit was lowered when fish were fed menhaden oil in the diet (LSF). The last significant interaction lipid source-protein source $\left(R^{2} 8 \% ; P<0.01\right)$ was associated with an increase in the area of mitochondria in fish fed a mix of fish and soya meal in the diet (PSFV) and rapeseed oil, compared with fish oil (LSF) $\left(0.32 v \cdot 0 \cdot 25 \mu \mathrm{m}^{2}\right)$. The opposite was observed when fish were fed pure fishmeal in the diets (PSF) (0.32 v. $0 \cdot 24 \mu \mathrm{m}^{2}$, respectively).

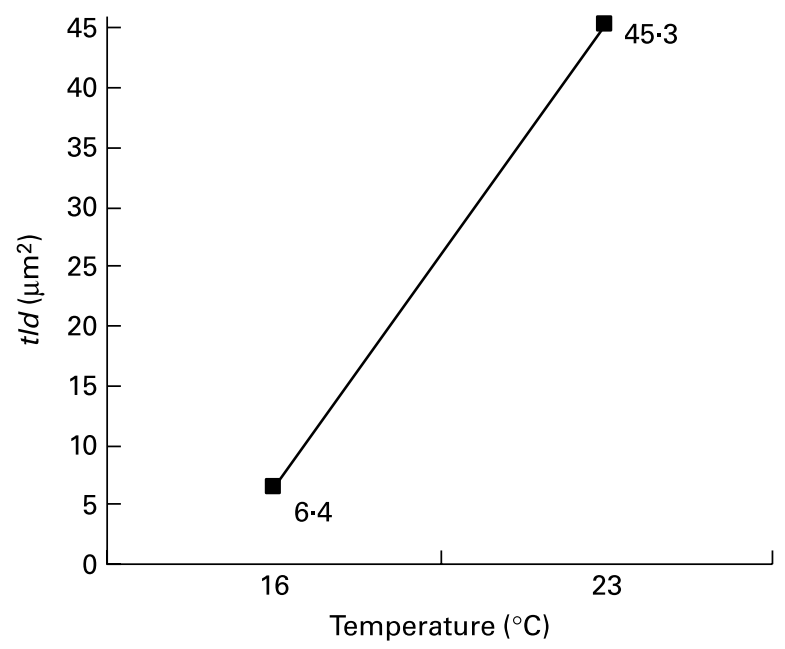

Fig. 4. Effect of temperature on the total area of lipid droplets per micrograph (tld) of female juvenile Eurasian perch (Perca fluviatilis L.) hepatocytes; tld = $n / d \times$ ald $\left(\mu \mathrm{m}^{2}\right)$, where $n / d$ is the number of lipid droplets per micrograph and ald is the mean area of lipid droplet per micrograph $\left(\mu \mathrm{m}^{2}\right)$. The impact of temperature on t/d expressed in percentage of variability $\left(R^{2}\right)$ is $61 \%$ $(P<0.001)$. CV residual mean square error $=64 \%$.

\section{Factor effects on other biological variables}

As shown in Table 4, specific growth rate (\%/d) was significantly affected by the temperature, the photoperiod and the lipid source $(50 \quad(P<0.001), 26 \quad(P<0.001)$ and $9 \%$ $(P<0.001)$, respectively). The best growth was recorded when a long photoperiod (16 h of light) or a high temperature $\left(23^{\circ} \mathrm{C}\right)$ or menhaden oil (LSF) were applied during the rearing experiment. Under low temperature $\left(16^{\circ} \mathrm{C}\right)$ and short photoperiod ( $8 \mathrm{~h}$ of light), fish gonads developed $(11.4 \%)$ and the liver $\left(I_{\mathrm{H}}\right)$ was bigger than in fish reared at $23^{\circ} \mathrm{C}$ under a long photoperiod ( $16 \mathrm{~h}$ of light). In case of no gonad maturation, energy was mainly stored in perivisceral tissues. The dietary protein source affected the $I_{\mathrm{H}}\left(R^{2} 34 \% ; P<0.001\right)$. In other words, when fishmeal was used, mean liver size was greater than with fishmeal and soya meal mix. The lipid

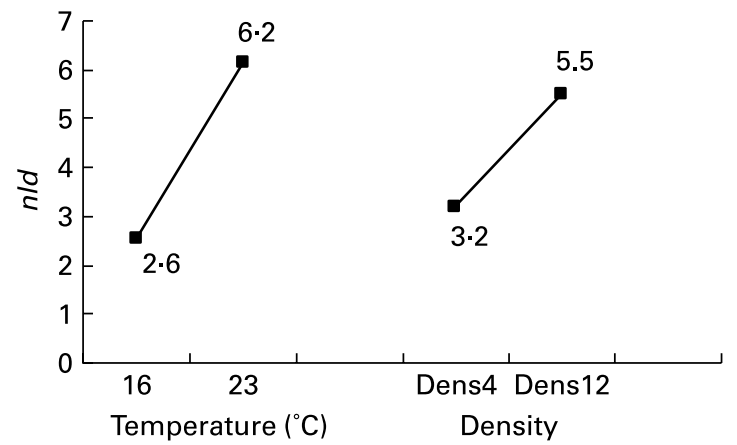

Fig. 5. Effects of temperature and expected final fish density on the number of lipid droplets per micrograph ( $n / d$ ) of female juvenile Eurasian perch (Perca fluviatilis L.) hepatocytes. Dens $4,4 \mathrm{~kg} / \mathrm{m}^{3}$; Dens $12,12 \mathrm{~kg} / \mathrm{m}^{3}$. The impact of temperature on $\mathrm{nld}$ expressed in percentage of variability $\left(R^{2}\right)$ is $30 \%(P<0.001)$. The impact of expected final fish density on $n / d$ expressed in percentage of variability $\left(R^{2}\right)$ is $12 \%(P<0.01)$. CV residual mean square error $=34 \%$. 


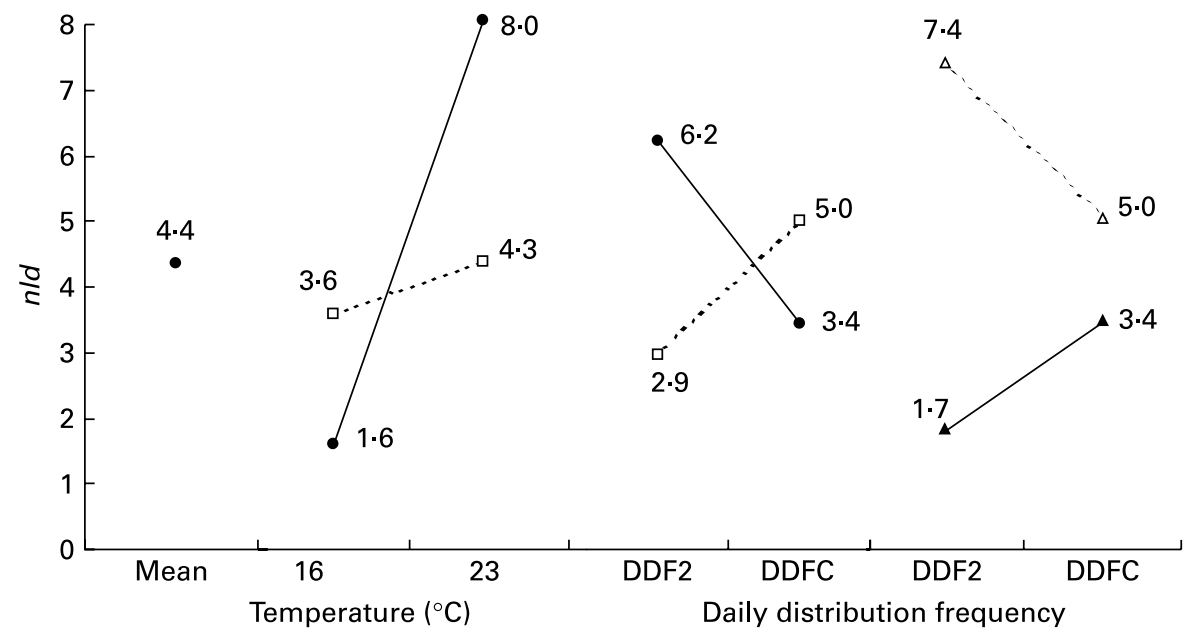

Fig. 6. Factor interaction effects on the number of lipid droplets per micrograph (n/d) of female juvenile Eurasian perch (Perca fluviatilis L.) hepatocytes. (-๑-), Fish-

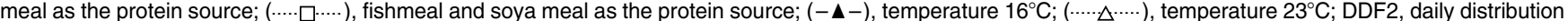
frequency two meals; DDFC, daily distribution frequency continuously. The impact of temperature and protein source on nld expressed in percentage of variability $\left(R^{2}\right)$ is $16 \%(P<0.001)$. The impact of daily distribution frequency and protein source on $n / d$ expressed in percentage of variability $\left(R^{2}\right)$ is $13 \%(P<0.01)$. The impact of daily distribution frequency and temperature on $n / d$ expressed in percentage of variability $\left(R^{2}\right)$ is $9 \%(P<0.01)$. CV residual mean square error $=34 \%$.

source influenced growth parameters but did not significantly affect the morphological criteria.

\section{Discussion}

In the present study, important variability within hepatocyte ultrastructure was observed according to treatment. Parenchymal cell morphology varied between typical fish hepatocyte as described by Takashima \& Hibiya ${ }^{(46)}$, and the so-called fat-storing cells of cultured species when lipid droplets were nearly filling the cytoplasm of numerous degenerated cells. In such conditions, excessive accumulations of fat into the cytoplasm were generally accompanied by nuclear atrophy and can be thus described as a pathological liver. Moreover, the variability of liver ultrastructural features in the present study was higher in comparison with a previous study on adult females of wild perch ${ }^{(5)}$. In this latter case, hepatic ultrastructure modifications were mainly enhanced by the vitellogenin production and no signs of impaired liver function were detected. In the hepatocytes of wild perch females and cultured perch, respectively, average nld was 11.47 and 4.36; area of lipid droplet per particle was 0.73 and $5.56 \mu \mathrm{m}^{2}$; tld was 8.17 and $25.8 \mu \mathrm{m}^{2}$; agly was 35.81 and $79.1 \mathrm{~mm}^{2}$; area of RER was 12.54 and $4.71 \%$; area of

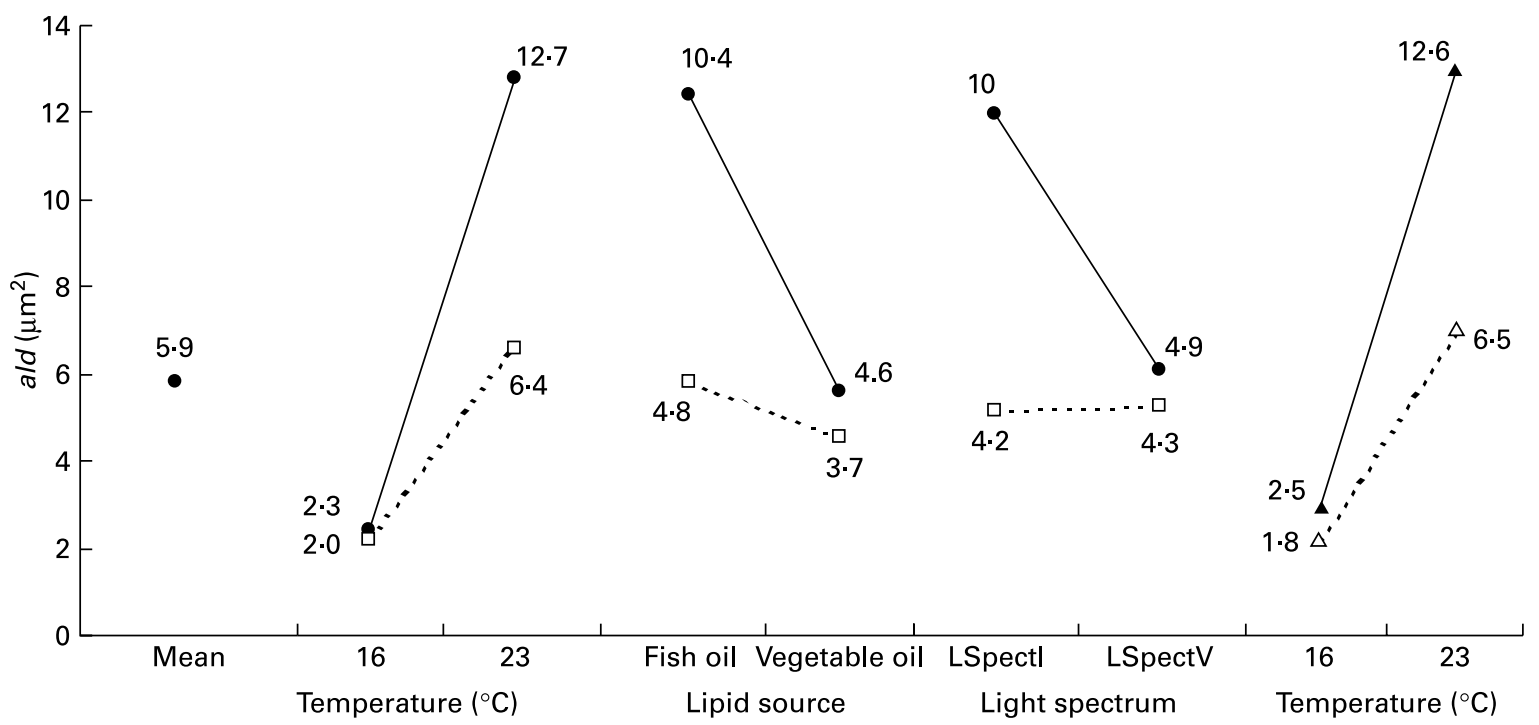

Fig. 7. Factor interaction effects on the mean area of lipid droplet per micrograph $\left(a / d ; \mu \mathrm{m}^{2}\right)$ of female juvenile Eurasian perch (Perca fluviatilis L.) hepatocytes.

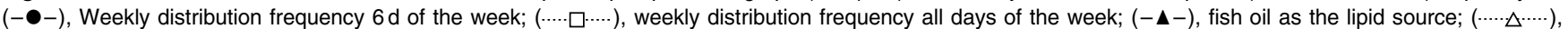
vegetable oil as the lipid source; LSpectl, light spectrum industrial white; LSpectV, light spectrum violet. The impact of temperature and weekly distribution frequency on ald expressed in percentage of variability $\left(R^{2}\right)$ is $7 \%(P<0.01)$. The impact of lipid source and weekly distribution frequency on ald expressed in percentage of variability $\left(R^{2}\right)$ is $4 \%(P<0.05)$. The impact of light spectrum and weekly distribution frequency on ald expressed in percentage of variability $\left(R^{2}\right)$ is $5 \%(P<0.05)$. The impact of temperature and lipid source on ald expressed in percentage of variability $\left(R^{2}\right)$ is $6 \%(P<0.05)$. CV residual mean square error $=41 \%$. 


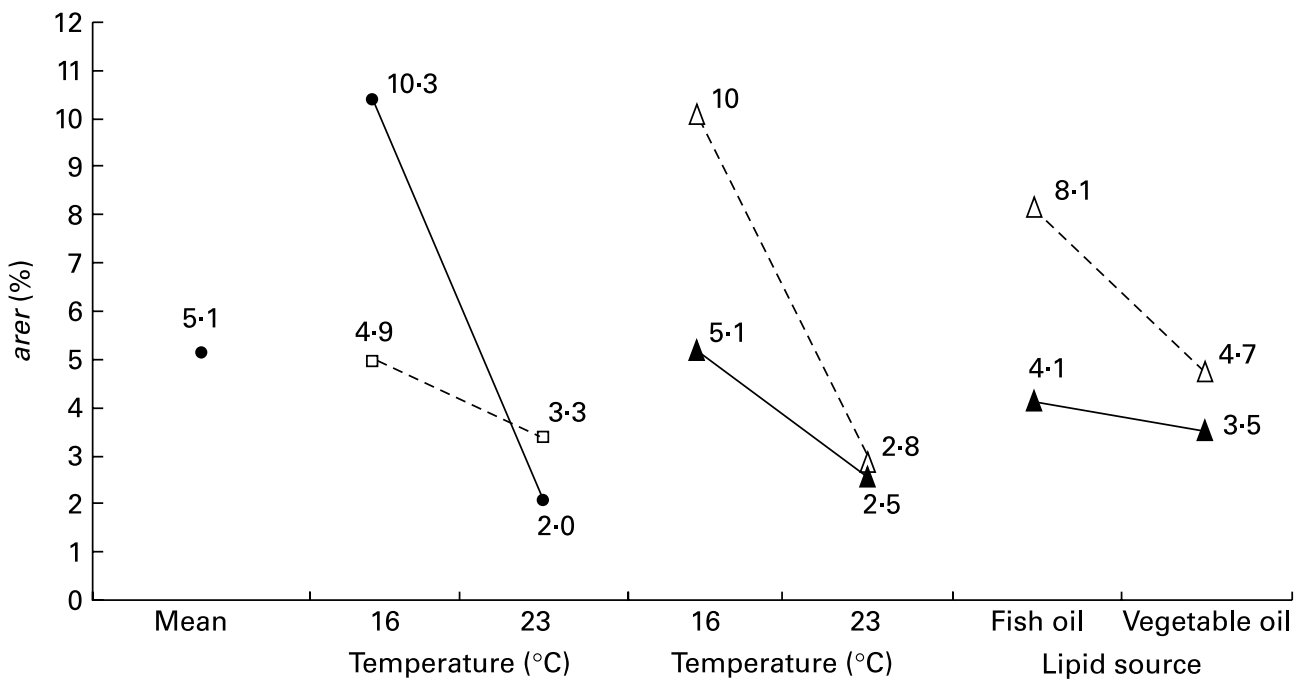

Fig. 8. Factor interaction effects on the area of rough endoplasmic reticulum per micrograph (arer, \%) of female juvenile Eurasian perch (Perca fluviatilis L.)

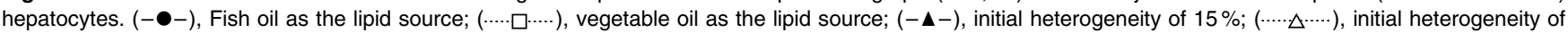
$30 \%$. The impact of temperature and lipid source on arer expressed in percentage of variability $\left(R^{2}\right)$ is $17 \%(P<0.001)$. The impact of temperature and initial heterogeneity on arer expressed in percentage of variability $\left(R^{2}\right)$ is $8 \%(P<0.01)$. The impact of lipid source and initial heterogeneity on arer expressed in percentage of variability $\left(R^{2}\right)$ is $3 \%(\mathrm{NS})$. CV residual mean square error $=31 \%$.

mitochondria was 0.55 and $0.27 \mu \mathrm{m}^{2}$; number of mitochondria was $19 \cdot 5$ and $43 \cdot 8$. Energy storage was more extended in cultured female perch than in wild ones, concomitantly to a modification of the organelle patterns usually observed in typical hepatocytes.

We have demonstrated the higher plasticity of lipid storage and RER development than those of mitochondria development and glycogen storage according to the different combinations of factors tested in the present experiment. It is well known that internal arrangement and peculiarities of hepatocyte organelles vary among species, age, season, sex, spawning period and nutritional condition ${ }^{(46)}$. The comparison of liver ultrastructure plasticity with other studies is rather difficult. There is a lack of similarity between experimental designs and no references of multifactorial approach. However, when analysed by electron microscopy, organelles previously mentioned are frequently the most influenced, regardless of the treatments applied such as inclusion of astaxanthin ${ }^{(26)}$, levels of dietary lipids, with or without added ethoxyquin ${ }^{(10)}$, lipid level and fishmeal quality ${ }^{(15)}$, diets and salinities ${ }^{(27)}$ and temperature ${ }^{(47)}$. Moreover, when histological modifications of the liver are observed using light microscopy, the significance of lipid storage plasticity (the number and size of lipid inclusions) becomes irrefutable, as demonstrated by Tucker et al. ${ }^{(48)}$, Fontagné et al. ${ }^{(49)}$, Robaina et al. ${ }^{(14)}$, Salhi et al. ${ }^{(50)}$, Morais et al. ${ }^{(51)}$ ', Caballero et al. ${ }^{(52,53)}$, Figueiredo-Silva et al. ${ }^{(54)}$ and Ruyter et al. ${ }^{(55)}$.

Alterations in the glycogen or mitochondria organisation of the liver linked to experimental feeding regimens are much less often reported. Hepatic steatosis and glycogen depletion in the liver coupled with poorer growth performance have been observed in rainbow trout ${ }^{(52)}$ and European glass eels (Anguilla anguilla) $^{(27)}$.

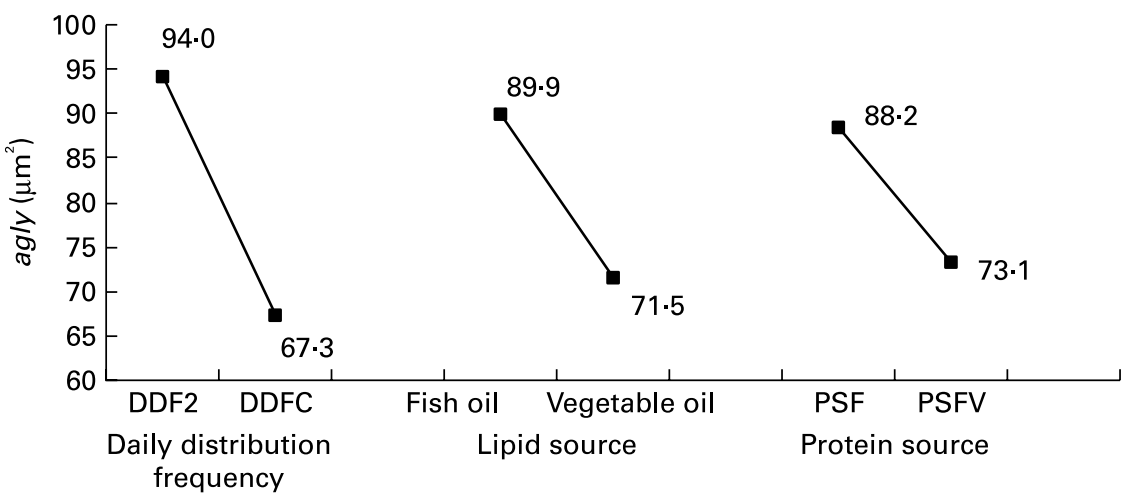

Fig. 9. Effects of daily distribution frequency, lipid source and protein source on the area of glycogen per micrograph $\left(a g / y\right.$; $\left.\mu m^{2}\right)$ of female juvenile Eurasian perch (Perca fluviatilis L.) hepatocytes. DDF2, daily distribution frequency two meals; DDFC, daily distribution frequency continuously; PSF, fishmeal as the protein source; PSFV, fishmeal and soya meal as the protein source. The impact of daily distribution frequency on agly expressed in percentage of variability $\left(R^{2}\right)$ is $23 \%(P<0.001)$. The impact of lipid source on agly expressed in percentage of variability $\left(R^{2}\right)$ is $8 \%(P<0.05)$. The impact of protein source on agly expressed in percentage of variability $\left(R^{2}\right)$ is $8 \%(P<0.05)$. CV residual mean square error $=18 \%$. 


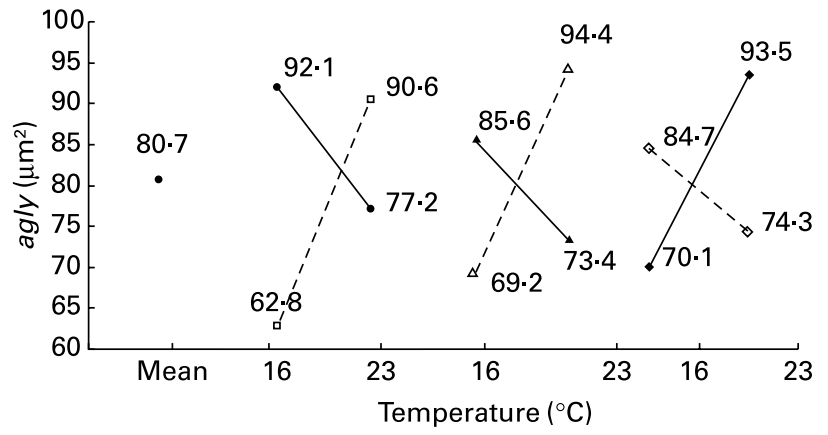

Fig. 10. Factor interaction effects on the area of glycogen per micrograph $\left(\right.$ agly, $\mu \mathrm{m}^{2}$ ) of female juvenile Eurasian perch (Perca fluviatilis L.) hepatocytes. (-๑-), Photoperiod $8 \mathrm{~h}$ light and $16 \mathrm{~h}$ dark; $(\cdots . . . \cdots)$, photoperiod $16 \mathrm{~h}$ light and $8 \mathrm{~h}$ dark; $(-\boldsymbol{\Delta}-)$, lipid content $17 \%$ on a wet-weight basis; $(\cdots .-\cdots .$.$) , lipid content 21 \%$ on a wet-weight basis; $(-\bullet-), 0 \%$ astaxanthin; $(--\diamond---), 0.4 \%$ astaxanthin. The impact of temperature and photoperiod on agly expressed in percentage of variability $\left(R^{2}\right)$ is $17 \%(P<0.01)$. The impact of temperature and lipid content on agly expressed in percentage of variability $\left(R^{2}\right)$ is $11 \%(P<0.05)$. The impact of temperature and astaxanthin enrichment on agly expressed in percentage of variability $\left(R^{2}\right)$ is $11 \%$ $(P<0.05)$. CV residual mean square error $=18 \%$

However, the location of the nucleus in a hepatocyte is often mentioned when describing the accumulation of lipid droplets, in order to evaluate the effect of feeding regimen on fish health ${ }^{(15,48,51,56)}$. When the nucleus does not occupy the centre of the cell, pathological accumulation of lipids can be suggested, even if it is reversible. In the present study, the location of the nucleus was not taken into account, but it could be recorded and mentioned in similar future studies. As suggested by Kestemont et al. ${ }^{(10)}$, we demonstrated that the accumulation of lipid droplets in the liver of perch is negatively correlated to RER surface and number of mitochondria, both essential organelles involved mainly in the protein synthesis and oxidation process, respectively. This could be interpreted as a sign of impaired liver function.

Among the twelve nutritional and husbandry conditions investigated, two major factors, temperature and lipid source, significantly affected the hepatocyte ultrastructure of intensively cultured Eurasian perch, but mostly in interaction between them or with other factors such as the protein source, the photoperiod, the diet lipid content, the initial heterogeneity or the daily distribution frequency. Hierarchically the temperature, as main effect or in interaction, is by far the dominant factor. Temperature changes are known to induce a wide range of physiological modifications in poikilotherms. For example, it may cause changes in the lipid composition of fish membranes in a process known as homoviscous adaptation ${ }^{(57)}$ or influence the fat content of fish tissue ${ }^{(58)}$. Atlantic salmon (Salmo salar) parr kept at $2^{\circ} \mathrm{C}$ showed higher muscle and carcass fat content than at $8^{\circ} \mathrm{C}^{(59)}$. Ingemansson et al. ${ }^{(60)}$ also demonstrated the higher fat accumulation in the dark muscle of rainbow trout (Oncorhynchus mykiss) acclimatised to cold temperature. GrisdaleHelland et al. ${ }^{(61)}$ showed that the $I_{\mathrm{H}}$ of Atlantic salmon held at low temperature was greater than those of fish raised at $12^{\circ} \mathrm{C}$. Ruyter et al. ${ }^{(55)}$ have shown that low temperature $\left(5^{\circ} \mathrm{C}\right)$ and high levels of soyabean oil (100\% soyabean oil) in the diet lead to an accumulation of fat in the liver of Atlantic salmon. On the contrary, in wall lizards (Hemidactylus frenatus), the hepatocyte ultrastructure study demonstrated that hepatocytes of animals adapted at $30^{\circ} \mathrm{C}$ displayed larger lipid inclusions compared with the hepatocytes of animals adapted at $20^{\circ} \mathrm{C}^{(47)}$. The authors also demonstrated an increase in the endoplasmic reticulum, number of mitochondria and peroxisomes at low temperature. Thus, disparities between results can be partly explained considering species and, within species, development stages and feeding history differences. But, it seems more and more evident that environmental temperature has no direct effect on tissue lipid contents but plays an indirect role through the feed intake increasing in case of higher temperature. Temperature interacts with feeding factors by modifying the mechanisms involved in supplying energy ${ }^{(58)}$. The present results confirm that rearing temperature influences the general metabolism, resulting in a modulation of the effects of the other factors that are related to diet quality or influence feed intake. In other words, factors related to diet quality or influencing the feed intake mainly intensify or compensate the effect of temperature at different levels of biological organisation: macroscopically by changes at the organ and tissue levels and microscopically at the

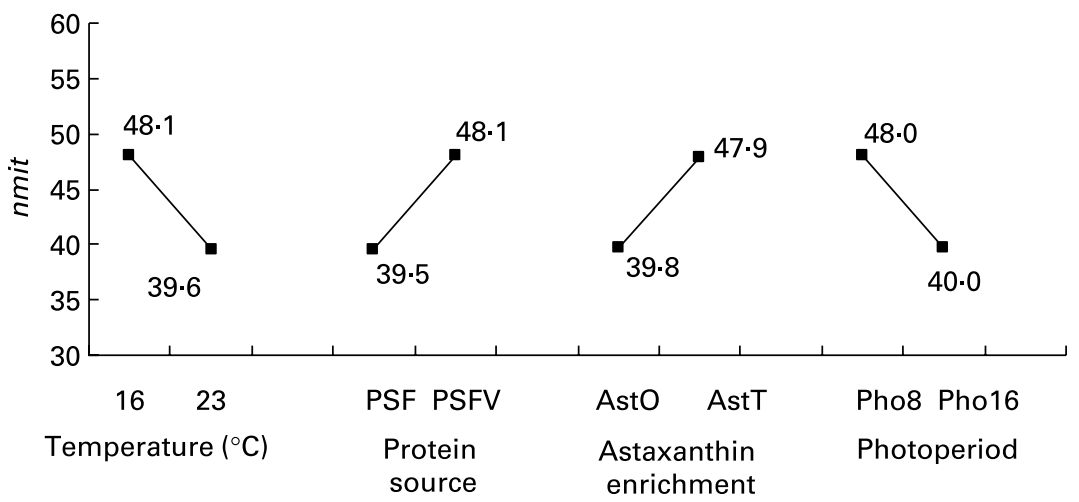

Fig. 11. Effects of temperature, protein source, astaxanthin enrichment and photoperiod on the number of mitochondria per micrograph ( $n$ mit) of female juvenile Eurasian perch (Perca fluviatilis L.) hepatocytes. PSF, fishmeal; PSFV, fish and soya meal; AstO, $0 \%$ astaxanthin; AstT, $0.4 \%$ astaxanthin; Pho8, $8 \mathrm{~h}$ light and $16 \mathrm{~h}$ dark; Pho16, $16 \mathrm{~h}$ light and $8 \mathrm{~h}$ dark. The impact of temperature on nmit expressed in percentage of variability $\left(R^{2}\right)$ is $10 \%(P<0.05)$. The impact of protein source on nmit expressed in percentage of variability $\left(R^{2}\right)$ is $10 \%(P<0.05)$. The impact of astaxanthin enrichment on $n$ mit expressed in percentage of variability $\left(R^{2}\right)$ is $9 \%(P<0.05)$. The impact of photoperiod on nmit expressed in percentage of variability $\left(R^{2}\right)$ is $10 \%(P<0.05)$. CV residual mean square error $=20 \%$ 


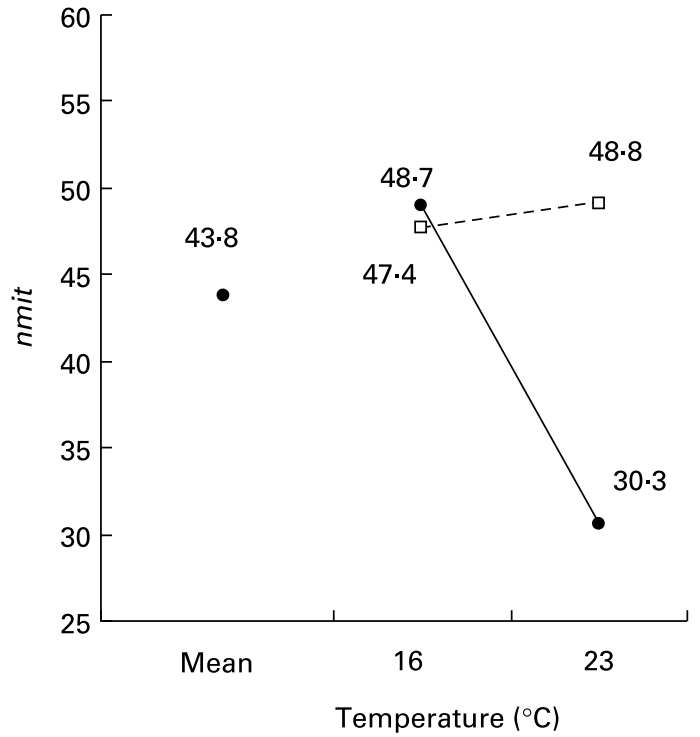

Fig. 12. Factor interaction effects of temperature and protein source on the number of mitochondria per micrograph (nmit) of female juvenile Eurasian

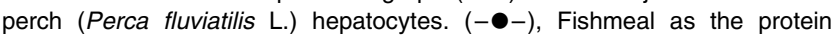
source; $(\cdots . . . \cdots \cdot . .$.$) , fishmeal and soya meal as the protein source. The impact$ of temperature and protein source on nmit expressed in percentage of variability $\left(R^{2}\right)$ is $12 \%(P<0.05)$. CV residual mean square error $=20 \%$.

cellular level by hepatic ultrastructure modifications occurring before macroscopic changes.

The fatty acid profile of diets is known to be very important in fish nutrition. Several authors have described liver alterations produced by nutritional origins. Large lipid vacuolisation of hepatocytes was observed when fish were fed vegetable oil $^{(27,48,50,52-54)}$ or when diets had imbalanced fatty acid composition and lipid levels ${ }^{(15,27,51,52)}$. Some authors refer to a physiological response to lipid excess that can indicate a well-fed status ${ }^{(15)}$ but not a pathological status as described by Mosconi-Bac ${ }^{(56)}$ in sea bass. Others refer to an excess level of unsaturated lipid in marine fish oil, which may present a greater risk from lipid peroxidation ${ }^{(54,62)}$. Verreth et al. ${ }^{(63)}$ demonstrated higher lipid vacuolisation according to different highly unsaturated fatty acid digestibility. Salhi et al. ${ }^{(50)}$ observed that lower polar lipid level affected the lipoprotein synthesis and consequently the transport of lipid from the liver to extrahepatic tissues. Caballero et al. ${ }^{(53)}$ reported that a high intake of highly unsaturated fatty acids (mainly EPA and DHA) prevents lipid accumulation as it induces lipid oxidation through the activation of $\beta$-oxidation. Fatty acid imbalances in the diet can also have an impact on liver lipid accumulation because of different elongation and desaturation enzyme affinities. In brief, modifications in lipid vacuolisation of the hepatocyte are linked with nutritional aspect such as the nature of diet, dietary fat balances, fatty acid profiles or fish digestive physiology. We argue that excessive lipid accumulation is probably reflecting hepatic dysfunctions of nutritional origin possibly related to disorders in the lipid metabolism. Moreover, this lipid accumulation is exacerbated when high rearing temperature is applied, inducing higher feed intake. In perch, optimal rearing temperature is $23^{\circ} \mathrm{C}$. In the present experiment, the effect of lipid source (fish oil $v$. vegetable oil) was obvious in decreasing the areas of lipid droplets, glycogen and, to a lesser extent, RER in the case of rapeseed oil in the diet. However, this lipid source effect was modulated according to the temperature and the weekly distribution frequency for ald and according to the temperature for arer (interactions). The fatty acid composition of the different oils explains partially such results. Regarding other studies, differences between results can also be explained by the variability of physiological responses according to species. Mourente et al. ${ }^{(64)}$ have shown an increase in the occurrence of

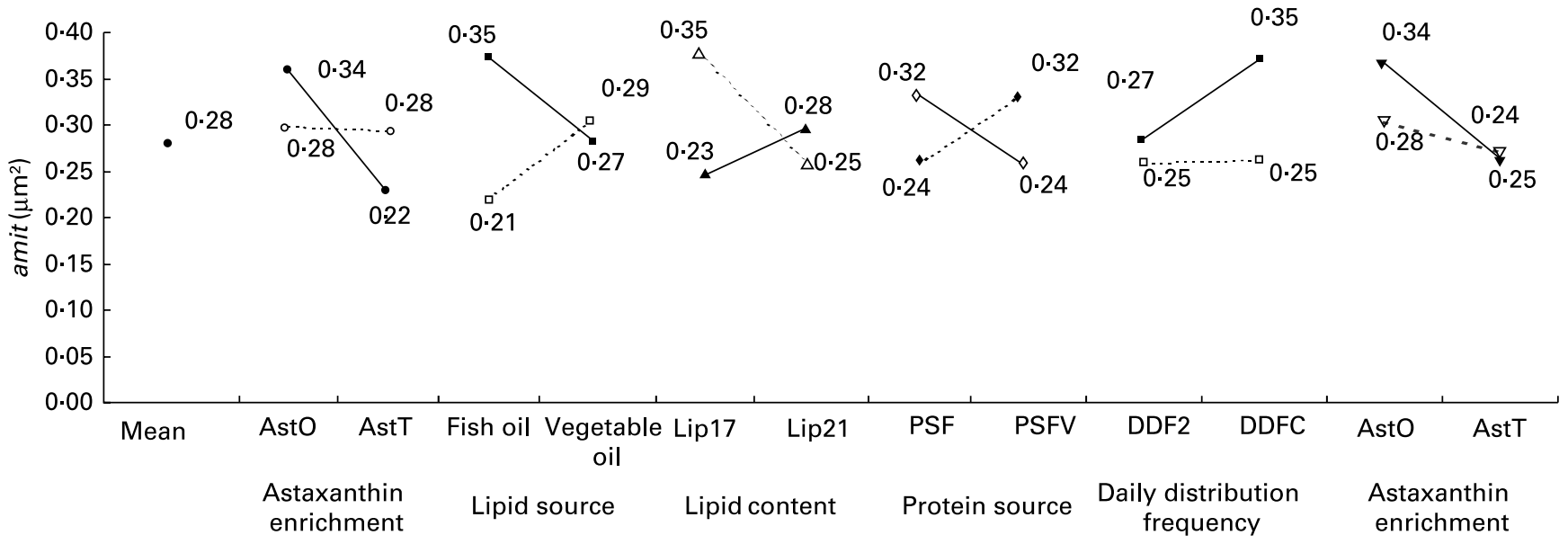

Fig. 13. Factor interaction effects on the mean area of mitochondria per micrograph (amit, $\left.\mu \mathrm{m}^{2}\right)$ of female juvenile Eurasian perch (Perca fluviatilis L.) hepato-

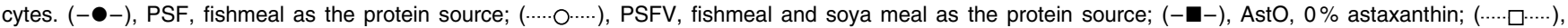
AstT, $0.4 \%$ astaxanthin; $(-\boldsymbol{\Delta}-)$, DDF2, daily distribution frequency two meals; $(\cdots-\cdots \cdots)$, DDFC, daily distribution frequency continuous; $(-\bullet-)$, fish oil as the lipid source; (-- $\diamond---)$, vegetable oil as the lipid source; $(-\nabla-)$, Lip17, lipid content $17 \%$ on a wet-weight basis; ( $\cdots .-\nabla \cdots .$.$) , Lip21, lipid content 21 \%$ on a wet-weight basis. The impact of astaxanthin enrichment and protein source on amit expressed in percentage of variability $\left(R^{2}\right)$ is $19 \%(P<0.001)$. The impact of lipid source and astaxanthin enrichment on amit expressed in percentage of variability $\left(R^{2}\right)$ is $18 \%(P<0.01)$. The impact of lipid content and daily distribution frequency on amit expressed in percentage of variability $\left(R^{2}\right)$ is $9 \%(P<0.01)$. The impact of protein source and lipid source on amit expressed in percentage of variability $\left(R^{2}\right)$ is $8 \%(P<0.01)$. The impact of daily distribution frequency and astaxanthin enrichment on amit expressed in percentage of variability $\left(R^{2}\right)$ is $5 \%(P<0.05)$. The impact of astaxanthin enrichment and lipid content on amit expressed in percentage of variability $\left(R^{2}\right)$ is $5 \%(P<0.05)$. CV residual mean square error $=9 \%$. 
Table 4. Effects of factors on growth parameters and morphological criteria in juvenile Eurasian perch (Perca fluviatilis L.)†

\begin{tabular}{|c|c|c|c|c|}
\hline & SGR $\ddagger$ & $I_{\mathrm{H}} \S$ & $I_{\mathrm{G}} \S$ & lŁ§ \\
\hline Mean & 0.42 & 1.87 & 4.54 & $3 \cdot 39$ \\
\hline CV RMSE (\%) & 13 & 14 & 22 & 14 \\
\hline Temp $R^{2}(\%)$ & $50^{\star \star \star}$ & $15^{\star \star}$ & $63^{\star \star \star}$ & $54^{\star \star \star}$ \\
\hline Pho $R^{2}(\%)$ & $26^{\star \star \star}$ & $7^{*}$ & $25^{\star \star \star}$ & $28^{\star \star \star}$ \\
\hline LS $R^{2}(\%)$ & $9^{\star \star \star}$ & & & \\
\hline $\mathrm{PS} R^{2}(\%)$ & & $34^{\star \star \star}$ & & \\
\hline Temp-Pho $R^{2}(\%)$ & & $24^{\star \star \star}$ & $11^{\star \star \star}$ & \\
\hline
\end{tabular}

SGR, specific growth rate $(\% / d) ; l_{\mathrm{H}}$, hepatosomatic index; $l_{\mathrm{G}}$, gonadosomatic index; $I_{L}$, liposomatic index; RMSE, residual mean square error; Temp, temperature; Pho, photoperiod; LS, lipid source; PS, protein source.

${ }^{\star} P<0.05,{ }^{* \star} P<0.01,{ }^{* \star *} P<0.001$.

† Values indicate the effects of factors or interactions, the impact of the factor on the measured variable expressed in percentage of variability $\left(R^{2}\right)$ and followed by the significance of the test.

$\ddagger$ SGR $(\% / d)=100 \times\left(\operatorname{Ln}\left(W_{\mathrm{f}}\right)-\operatorname{Ln}\left(W_{\mathrm{i}}\right)\right) / \Delta T$, where $W_{\mathrm{i}}$ and $W_{\mathrm{f}}$ are initial and final weights (g), respectively, and $\Delta T$ is the duration of the experiment (d).

$\S$ The $I_{\mathrm{H}}, I_{\mathrm{G}}$ and $I_{\mathrm{L}}$ were calculated as: $y=100 \times x / M$, where $y$ is the index, $M$ is the mass $(\mathrm{g})$ of the fish, and $x$ is the mass $(\mathrm{g})$ of the liver, gonad or perivisceral fat.

variable-sized vacuoles and large amounts of lipid droplets within hepatocytes in the case of partial replacement of fish oil in the diet of European sea bass (Dicentrarchus labrax L.) by rapeseed oil. Another study on salmonids demonstrated higher or lower total lipid contents of liver in fish fed vegetable oils (blend of linseed and rapeseed oils) or fish oil, according to species ${ }^{(65)}$.

Globally, numerous interaction effects between temperature, lipid source and other nutritional factors such as daily and weekly distribution frequencies, protein source or factors such as expected final density, initial heterogeneity and Ast, were also observed. Most of these effects can be explained considering quantities of ingested food. For example, in the case of $7 \mathrm{~d}$ feeding frequency the ald was smaller than in the case of $6 \mathrm{~d}$ feeding frequency. In this case, fish appear to be able to adapt their feed intake after a period of undernutrition by hyperphagia ${ }^{(66)}$. Interactions between weekly distribution frequency and temperature corroborated this result because differences in area of lipid droplets were more pronounced at $23^{\circ} \mathrm{C}$ than at $16^{\circ} \mathrm{C}$.

The effect of Ast was less pronounced than previously cited factors, but nevertheless interesting. Literature data on the effects of astaxanthin-enriched diets on fish metabolism are scarce. However, astaxanthin as a carotenoid is known to be an efficient antioxidant in fish. The liver is thought to be the major site for carotenoid pigment metabolism ${ }^{(67,68)}$. Any effect of astaxanthin supplementation would be apparent in the histology of the liver ${ }^{(26)}$. The present results suggest that astaxanthin-enriched diets probably exerted their effects on the area of mitochondria and to a lesser extent on the number of mitochondria and area of glycogen per micrograph. Segner et al. ${ }^{(26)}$ observed significantly higher glycogen deposition in the liver compared with their controls in Oreochromis niloticus fed diets supplemented with astaxanthin. In contrast, Page et al. ${ }^{(69)}$ did not observe any differences in glycogen deposition in the livers of carotenoid-treated Oncorhynchus mykiss. However, as they indicated, rearing temperatures between these studies were different and consequently hepatocellular structures were difficult to compare ${ }^{(69)}$. The present study suggested an interaction effect between temperature and Ast on glycogen development, corroborating the findings of both authors. We also demonstrated the impact of Ast, in interactions with diet lipid content, lipid or protein sources, weekly and daily distribution frequencies, on the area of mitochondria (amit). We also showed that astaxanthin apparently increased the number of mitochondria. Whether this is significant is difficult to establish, given the lack of similar studies in the literature. However, the present results lend support to the assumption that astaxanthin has a positive metabolic effect on perch, supported by the fact that $0.4 \%$ astaxanthin in the diet was associated with a lower area of mitochondria (amit), when $0 \%$ Ast was linked with comparatively higher values of amit.

Numerous studies have demonstrated an increase in the $I_{\mathrm{H}}$ and liver lipid content with increasing levels of dietary $\mathrm{fat}^{(70-73)}$. In the present study, the lipid content factor analysed with the levels of 17 and $21 \%$ dietary lipid does not support this idea. This could be due to a too small difference between the two dietary lipid contents tested. Moreover, a previous experiment with Eurasian perch reared at $23^{\circ} \mathrm{C}$ as the optimal rearing temperature demonstrated that $17 \%$ dietary lipid is already increasing the degree of vacuolation in hepatocytes.

The accumulation of energy into the liver is not only under the dependence of dietary lipid content but can be modulated according to the quality of fishmeal. Caballero et al. ${ }^{(15)}$ have shown in gilthead sea bream that $27 \%$ dietary lipid with highquality meal led to a hepatic steatosis while, at the same lipid level but with low-quality fishmeal, hepatic morphology was not pathological. Thus, when dietary lipid or energy exceeds the capacity of the hepatic cells to oxidise fatty acids, or when protein metabolism is impaired, the result is a large synthesis and deposition of TAG in vacuoles, leading to steatosis ${ }^{(53)}$.

The determination of hepatocyte ultrastructure build-up as presented here is at its simplest; it could, however, be more complex because of possible confused significant interactions.

\section{Conclusion}

The rearing temperature through its influences in the general metabolic activity seems to be the main factor influencing directly but the most often in strong interaction with other nutritional or environmental factors, principally lipid droplet accumulation and RER development. Factors related to diet quality or influencing the feed intake mainly intensify or compensate the effect of temperature at different levels of biological organisation. In comparison with a previous study on adult females of wild perch ${ }^{(5)}$ we demonstrated the higher variability of liver ultrastructural features in the present study with complex determination based on interaction between factors.

Today, liver histological changes are often observed by scientists to prove dietary effect on the transport and metabolism of fat in fish ${ }^{(52)}$. In future experiments, dedicated to the evaluation of liver status through ultrastructure analysis, it could be beneficial to study the lipid accumulation, the RER development as well as the nucleus location.

We argue that in the context of sustainable aquaculture, guaranteeing liver functional integrity and healthy fish, as well as ensuring profitable production, could be achieved by using an adequate combination of nutritional and husbandry factors. 


\section{Acknowledgements}

The authors thank the French Research Ministry which allowed the realisation of the work as part of the project AQS F7-2001: System of production and the technological and nutritional quality of the perch and for their partnership (Laboratoire INRA de Nutrition des Poissons, St Pée sur Nivelle; Société TAG; Société BioMar; Filière Lorraine d'Aquaculture Continentale). The authors express their gratitude to the staff of the electron microscopy laboratory of Namur University, especially M-F Six-Boulanger, for their contribution in the preparation of electron micrographs.

\section{References}

1. Bell JG, McEvoy J, Webster JL, McGhee F, Millar RM \& Sargent JR (1998) Flesh lipid and carotenoid composition of Scottish farmed Atlantic salmon (Salmo salar). J Agric Food Chem 46, 119-127.

2. Regost C, Arzel J, Cardinal M, Robin J, Laroche M \& Kaushik SJ (2001) Dietary lipid level, hepatic lipogenesis and flesh quality in turbot (Psetta maxima). Aquaculture 193, 291-309.

3. Sulistyo I, Rinchard J, Fontaine P, Gardeur J-N, Capdeville B \& Kestemont P (1998) Reproductive cycle and plasma levels of sex steroids in female Eurasian perch Perca fluviatilis. Aquat Living Resour 11, 101-110.

4. Sulistyo I, Fontaine P, Rinchard J, Gardeur J-N, Migaud H, Capdeville B \& Kestemont P (2000) Reproductive cycle and plasma levels of steroids in male Eurasian perch Perca fluviatilis. Aquat Living Resour 13, 99-106.

5. Blanchard G, Druart X \& Kestemont P (2005) Lipid content and fatty acid composition of target tissues in wild Perca fluviatilis females in relation to hepatic status and gonad maturation. J Fish Biol 66, 73-85.

6. Brown PB, Dabrowski K \& Garling DL (1996) Nutrition and feeding of yellow perch (Perca flavescens). J Appl Ichthyol 12, 171-174.

7. Mélard C, Kestemont P \& Grignard JC (1996) Intensive culture of juvenile and adult Eurasian perch ( $P$. fluviatilis): effect of major biotic and abiotic factors on growth. J Appl Ichthyol 12, $175-180$.

8. Fontaine P, Gardeur J-N, Kestemont P \& Georges A (1997) Influence of feeding level on growth, intraspecific weight variability and sexual growth dimorphism of Eurasian perch Perca fluviatilis L. reared in a recirculating system. Aquaculture 157, $1-9$.

9. Kestemont P, Vandeloise E, Brown P, Mélard C \& Fontaine P (1997) Effects of casein-based diets containing different levels of lipids on survival, growth, and nutritional status of Eurasian perch. In Perca fluviatilis. Island Aquaculture and Tropical Aquaculture, 2nd International Workshop on Aquaculture of Percid Fish, pp. 333-334 [L Creswell and Y Harache, editors]. Ostend, Belgium: EAS Special Publication.

10. Kestemont P, Vandeloise E, Mélard C, Fontaine P \& Brown PB (2001) Growth and nutritional status of Eurasian perch, Perca fluviatilis, fed graded levels of dietary lipids with or without added etoxyquin. Aquaculture 203, 85-99.

11. Xu X \& Kestemont P (2002) Lipid metabolism and fatty acid composition of Eurasian perch tissues as influenced by dietary fat. Lipids 37, 297-304.

12. Xu X, Fontaine P, Mélard C \& Kestemont P (2002) Effect of dietary fat levels on growth, feed efficiency and biochemical compositions of Eurasian perch Perca fluviatilis. Aquac Int 9, 437-449.

13. Bautista MN \& De la Cruz MC (1988) Linoleic ( $\omega 6)$ and linolenic $(\omega 3)$ acids in the diet of fingerling milkfish (Chanos chanos Forsskal). Aquaculture 71, 347-358.
14. Robaina L, Izquierdo MS, Moyano FJ, Socorro J, Vergara JM \& Montero D (1998) Increase of the dietary $n-3 / n-6$ fatty acid ratio and addition of phosphorus improves liver histological alterations induced by feeding diets containing soybean meal to gilthead seabream, Sparus aurata. Aquaculture 161, 281-293.

15. Caballero MJ, Lòpez-Calero G, Socorro J, Roo FJ, Izquierdo MS \& Fernàndez AJ (1999) Combined effect of lipid level and fish meal quality on liver histology of gilthead seabream (Sparus aurata). Aquaculture 179, 277-290.

16. Ibeas C, Izquierdo MS \& Lorenzo A (1994) Effects of different levels of $n-3$ highly unsaturated fatty acids on growth and fatty acid composition of juvenile gilthead seabream (Sparus aurata). Aquaculture 127, 177-188.

17. Bell JG, Tocher DR, MacDonald M \& Sargent JR (1995) Effects of dietary borage oil (enriched in $\alpha$-linoleic acid, $18: 3(n-6))$ or marine fish oil (enriched in eicosapentaenoic acid, 20:5(n-3)) on growth, mortalities, liver histopathology and lipid composition of juvenile turbot (Scophthalmus maximus). Fish Physiol Biochem 14, 373-383.

18. Hinton DE, Lantz RC, Hampton JA, McCuskey PR \& McCuskey RS (1987) Normal versus abnormal structure: considerations in morphologic responses of teleosts to pollutants. Environ Health Perspect 71, 139-146.

19. Escaffre AM \& Bergot P (1986) Morphologie quantitative du foie des alevins de truite arc-en-ciel (Salmo gairdnerii) issus de gros ou de petits œufs: incidence de la date de premier repas (Quantitative liver morphology of rainbow trout (Salmo gairdnerii) fry resulting from large or small eggs: incidence of the date of the first meal). Arch Hydrobiol 107, 331-348.

20. Braunbeck T, Storch V \& Nagel R (1989) Sex-specific reaction of liver ultrastructure in Zebra fish (Brachydanio rerio) after prolonged sublethal exposure to 4-nitrophenol. Aquatic Toxicol 14, 185-202.

21. Braunbeck T, Storch V \& Bresch H (1990) Species-specific reaction of liver ultrastructure in Zebra fish (Brachydanio rerio) and trout (Salmo gairdneri) after prolonged exposure to 4-chloroaniline. Arch Environ Contam Toxicol 19, 405-418.

22. Braunbeck T \& Völkl A (1991) Induction of biotransformation in the liver of eel (Anguilla anguilla) by sublethal exposure to dinitro-o-cresol: an ultrastructural and biochemical study. Ecotoxicol Environ Saf 21, 109-127.

23. Arnold H, Pluta HJ \& Braunbeck T (1996) Cytological alterations in the liver of rainbow trout Oncorhynchus mykiss after prolonged exposure to low concentrations of waterborne endosulfan. Dis Aquat Org 25, 39-52.

24. Arnold H, Pluta HJ \& Braunbeck T (1996) Sublethal effects of prolonged exposure to disulfoton in rainbow trout (Oncorhynchus mykiss): cytological alterations in the liver by a potent acetylcholine esterase inhibitor. Ecotoxicol Environ Saf 34, 43-55.

25. Quabius ES, Nolan DT, Balm PHT \& Wendelaar Bonga SE (1998) The influence of polychlorinated biphenyl 126 on tilapia (Oreochromis mossambicus) liver. Comp Biochem Physiol A 120, $57-63$.

26. Segner $\mathrm{H}$, Arend $\mathrm{P}$, Von Poeppinghausen $\mathrm{K}$ \& Schmidt $\mathrm{H}$ (1989) The effect of feeding astaxanthin to Oreochromis niloticus and Colisa labiosa on the histology of the liver. Aquaculture 79, 381-390.

27. Rodríguez A, Gisbert E, Rodríguez G \& Castelló-Orvay F (2005) Histopathological observations in European glass eels (Anguilla anguilla) reared under different diets and salinities. Aquaculture 244, 203-214.

28. Box GEP, Hunter WG \& Stuart J (1978) An introduction to design, data analysis and model building. In Statistics for Experimenters, pp. 374-434. New York: Wiley Interscience. 
29. Babiak I, Brzuska E \& Perkowski J (2000) Fractional factorial design of screening experiments on cryopreservation of fish sperm. Aquat Res 31, 273-282.

30. Ruohonen K, Kettunen J \& King J (2001) Experimental design in feeding experiments. In Proceedings of Food Intake in Fish, pp. 88-107 [D Houlihan, T Boujard and M Jobling, editors]. Oxford: Blackwell Sciences.

31. Torstensen BE, Lie O \& Hamre KA (2001) A factorial experimental design for investigation of effects of dietary lipid content and pro- and antioxidants on lipid composition in Atlantic salmon (Salmo salar) tissues and lipoproteins. Aquac Nutr 7, 265-276

32. Hamre K, Christiansen R, Waagbo R, Maage A, Torstensen BE, Lygren B, Lie O, Wathne E \& Albrektsen S (2004) Antioxidant vitamins, minerals and lipid levels in diets for Atlantic salmon (Salmo salar, L.): effects on growth performance and fillet quality. Aquac Nutr 10, 113-123.

33. Wang N, Gardeur J-N, Henrotte E, Marie M, Kestemont P \& Fontaine $\mathrm{P}$ (2006) Determinism of the induction of the reproductive cycle in female Eurasian perch, Perca fluviatilis: identification of environmental cues and permissive factors. Aquaculture 261, 706-714.

34. Mairesse G, Thomas M, Gardeur J-N \& Brun-Bellut J (2007) Effects of dietary factors, stocking biomass and domestication on the nutritional and technological quality of the Eurasian perch Perca fluviatilis. Aquaculture 262, 86-94.

35. Gardeur J-N, Mathis N, Kobilinsky A \& Brun-Bellut J (2007) Simultaneous effects of nutritional and environmental factors on growth and flesh quality of Perca fluviatilis using a fractional factorial design study. Aquaculture 273, 50-63.

36. Mathis N, Feidt C \& Brun-Bellut J (2003) Influence of protein/ energy ratio on carcass quality during the growing period of Eurasian perch (Perca fluviatilis). Aquaculture 217, 453-464.

37. Kobilinsky A (1997) Les plans factoriels (Factorial plans). In Plans d'Expériences: Applications à l'Entreprise (Experience Plans: Applications to Enterprise), pp. 69-209 [JJ Droesbeke and J Fine, editors]. Paris: Technip.

38. Chen H \& Cheng CS (2000) Uniqueness of some resolution IV two-level regular fractional factorial designs. J Discrete Math $13,571-575$.

39. Kobilinsky A \& Monod H (1995) Juxtaposition of regular factorial designs and the complex linear model. Scand J Stat 22, 223-254.

40. Eaton AD, Clesceri LS \& Greenberg AE (1995) Standard Methods for Examination of Water and Wastewater. Washington, DC: American Public Health Association.

41. Folch J, Lees M \& Sloane Stanley GH (1957) A simple method for isolation and purification of total lipides from animal tissues. $J$ Biol Chem 29, 497-509.

42. Chen IS, Shen CSJ \& Sheppard AJ (1981) Comparison of methylene chloride and chloroform for extraction of fats from food products. J Am Oil Chem Soc 58, 599-601.

43. Santha NC \& Ackman RG (1990) Nervonic acid versus tricosanoic acid as internal standards in quantitative gas chromatographic analyses of fish oil longer-chain $n$-3 polyunsaturated fatty acid methyl esters. J Chromatogr Biomed Appl 553, 1-10.

44. Kobilinsky A (2000) Reparametrisation of interest in non-uniform factorial designs. Linear Algebra Appl, 321, 239-280.

45. Daniel C (1959) Use of half-normal plots in interpreting factorial two-level experiments. Technometrics 1, 311-341.

46. Takashima F \& Hibiya T (1995) An Atlas of Fish Histology: Normal and Pathological Features. Tokyo: Kodansha Ltd.

47. de Brito-Gitirana L \& Storch V (2002) Temperature induced alterations in the liver of wall lizard (Hemidactylus frenatus): morphological and biochemical parameters. Micron 33, 667-672.

48. Tucker JW, Lellis WA, Vermeer GK, Roberts DE \& Woodward PN (1997) The effects of experimental starter diets with different levels of soybean or menhaden oil on red drum (Sciaenops ocellatus). Aquaculture 149, 323-339.

49. Fontagné S, Geurden I, Escaffre AM \& Bergot P (1998) Histological changes induced by dietary phospholipids in intestine and liver of common carp (Cyprinus carpio) larvae. Aquaculture 161, 213-223.

50. Salhi M, Hernandez-Cruz CM, Bessonart M, Izquierdo MS \& Fernandez-Palacios H (1999) Effect of different dietary polar lipid levels and different $n$-3 HUFA content in polar lipids on gut and liver histological structure of gilthead sea bream (Sparus aurata) larvae. Aquaculture 179, 253-263.

51. Morais S, Bell GJ, Robertson DA, Roy WJ \& Morris PC (2001) Protein/lipid ratios in extruded diets for Atlantic cod (Gadus morhua L.): effects on growth, feed utilisation, muscle composition and liver histology. Aquaculture 203, 101-119.

52. Caballero MJ, Obach A, Rosenlund G, Montero D, Gisvold M \& Izquierdo MS (2002) Impact of different lipid sources on growth, lipid digestibility, tissue fatty acid composition and histology of rainbow trout, Oncorhynchus mykiss. Aquaculture 214, 253-271.

53. Caballero MJ, Izquierdo MS, Kjorsvik E, Fernandez AJ \& Rosenlund G (2004) Histological alterations in the liver of sea bream, Sparus aurata L., caused by short- or long-term feeding with vegetable oils. Recovery of normal morphology after feeding fish oil as the sole lipid source. J Fish Dis 27, 531-541.

54. Figueiredo-Silva A, Rocha E, Dias J, Silva P, Rema P, Gomes E \& Valente LMP (2005) Partial replacement of fish oil by soybean oil on lipid distribution and liver histology in European sea bass (Dicentrarchus labrax) and rainbow trout (Oncorhynchus mykiss) juveniles. Aquac Nutr 11, 147-155.

55. Ruyter B, Moya-Falcón C, Rosenlund G \& Vegusdal A (2006) Fat content and morphology of liver and intestine of Atlantic salmon (Salmo salar): effects of temperature and dietary soybean oil. Aquaculture 252, 441-452.

56. Mosconi-Bac N (1987) Hepatic disturbances induced by artificial feed in the sea bass (Dicentrarchus labrax) during the first year of life. Aquaculture 153, 251-261.

57. Røsjø C, Berg $\mathrm{T}$, Manum $\mathrm{K}$, Gjoen $\mathrm{T}$, Magnusson $\mathrm{S}$ \& Thomassen MS (1994) Effects of temperature and dietary $n-3$ and $n-6$ fatty acids on endocytic processes in isolated rainbow trout (Oncorhynchus mykiss, Walbaum) hepatocytes. Fish Physiol Biochem 13, 119-132.

58. Corraze G, Larroquet L \& Médale F (1999) Alimentation et dépôts lipidiques chez la truite arc-en-ciel, effet de la temperature d'élevage (Lipidic food and deposits in the rainbow trout, effect of the temperature of breeding). Prod Anim 12, 249-256.

59. Jobling M \& Bendiksen EA (2003) Dietary lipids and temperature interact to influence tissue fatty acid compositions of Atlantic salmon, Salmo salar L., parr. Aquac Res 34, 1423-1441.

60. Ingemansson T, Olsson NU \& Kaufmann P (1993) Lipid composition of light and dark muscle of rainbow trout (Oncorhynchus mykiss) after thermal acclimation: a multivariate approach. Aquaculture 113, 153-165.

61. Grisdale-Helland B, Ruyter B, Rosenlund G, Obach A, Helland SJ, Sandberg MG, Standal H \& Rosjo C (2002) Influence of high contents of dietary soybean oil on growth, feed utilization, tissue fatty acid composition, heart histology and standard oxygen consumption of Atlantic salmon (Salmo salar) raised at two temperatures. Aquaculture 207, 311-329.

62. Bell JG, Tocher DR, MacDonald FM \& Sargent JR (1995) Effects of dietary borage oil (enriched in $\gamma$-linoleic acid, $18: 3(n-6))$ or marine fish oil (enriched in eicopentaenoic acid, $20: 5(n-3))$ on growth, mortalities, liver histopathology and lipid composition of juvenile turbot (Scophthalmus maximus). Fish Physiol Biochem 14, 373-383.

63. Verreth J, Coppoolse J \& Segner H (1994) The effect of low HUFA- and high HUFA-enriched Artemia, fed at different feeding 
levels, on growth, survival, tissue fatty acids and liver histology of Clarias gariepinus larvae. Aquaculture 126, 137-150.

64. Mourente G, Good JE \& Bell JG (2005) Partial substitution of fish oil with rapeseed, linseed and olive oils in diets for European sea bass (Dicentrarchus labrax L.): effects on flesh fatty acid composition, plasma prostaglandins $E_{2}$ and $F_{2 \alpha}$, immune function and effectiveness of a fish oil finishing diet. Aquac Nutr 11, 25-40.

65. Tocher DR, Bell JG, MacGlaughlin P, McGhee F \& Dick JR (2001) Hepatocyte fatty acid desaturation and polyunsaturated fatty acid composition of liver on salmonids: effects of dietary vegetable oil. Comp Biochem Physiol 130, 257-270.

66. Houlihan D, Boujard T \& Jobling M (2001) Food Intake in Fish. Oxford: Blackwell Science Ltd.

67. Hardy RW, Torrissen OJ \& Scott TM (1990) Absorption and distribution of ${ }^{14} \mathrm{C}$-labelled canthaxanthin in rainbow trout (Oncorhynchus mykiss). Aquaculture 87, 331-340.

68. Metusalach J, Synowiecki J, Brown J \& Shahidi F (1996) Deposition and metabolism of dietary canthaxanthin in different organs of Arctic charr (Salvelinus alpinus L.). Aquaculture 142, 99-106.
69. Page GI, Russell PM \& Davies SJ (2005) Dietary carotenoid pigment supplementation influences hepatic lipid and mucopolysaccharide levels in rainbow trout (Oncorhynchus mykiss). Comp Biochem Physiol B 142, 398-402.

70. Jobling M, Knudsen R, Pedersen PS \& Dos Santos J (1991) Effects of dietary composition and energy content on the nutritional energetics of cod, Gadus morhua. Aquaculture 92, 243-257.

71. Lanari D, Poli BM, Ballestrazzi R, Lupi P, D’Agaro E \& Mecatti M (1999) The effects of dietary fat and NFE levels on growing European sea bass (Dicentrarchus labrax L.). Growth rate, body and fillet composition, carcass traits and nutrient retention efficiency. Aquaculture 179, 351-364.

72. Peres H \& Oliva-Teles A (1999) Effect of dietary lipid level on growth performance and feed utilisation by European sea bass juveniles (Dicentrarchus labrax). Aquaculture 179, 325-334.

73. Santinha PJM, Médale F, Corraze G \& Gomes EFS (1999) Effects of the dietary protein:lipid ratio on growth and nutrient utilization in gilthead seabream (Sparus aurata L.). Aquacult Nutr 5, 147-156. 